\title{
O PROCESSO DE COLAPSO GRAVITACIONAL DA SEÇÃO MARINHA DA BACIA DA FOZ DO AMAZONAS - MARGEM EQUATORIAL BRASILEIRA*
}

\author{
Rodrigo Perovano ${ }^{1}$, Antonio Tadeu dos Reis ${ }^{2}$, Cleverson Guizan Silva ${ }^{1}$, Bruno C. Vendeville ${ }^{3}$, \\ Christian Gorini ${ }^{4}$, Valterlene de Oliveira ${ }^{5}$ e Érika Ferreira da Silva Araújo ${ }^{1}$
}

Recebido em 17 junho, 2009 / Aceito em 11 setembro, 2009

Received on June 17, 2009 / Accepted on September 11, 2009

\begin{abstract}
Gravitational deformation affects the entire marine sequences of the Foz do Amazonas basin, including the sedimentary successions of the Amazon Fan. Associated gravity-driven structures, imaged by 2D multichannel seismic profiles, were driven by gravity in a linked extensional-contractional system gliding on weak levels, and driven by sedimentary loading and by the bathymetric slope. Sliding of the sedimentary section took place along distinct décollement surfaces and, apparently, at different stages of the margin's evolution. At least three main stratigraphic levels have acted as décollement surfaces, at either regional or local scale. Gravity-driven deep-water fold-and-thrust belts stand as the most remarkable structures along the margin. Their geometry and structural complexity vary along strike, owing to lateral changes in the development of the Amazon fan's depocenters. These structures are significantly more complex along the Northwestern Compartment, where the major margin's depocenters are located, exhibiting evidence of long-lasting deformation from multiple partially-overlapping fronts. In the South-eastern Compartment, the system is restricted to a pair of active reverse faults causing no major sea-bottom relief (inactivated belt). At local scale, antithetic normal growth faults detach on an upper décollement level and exert structural control on the segmentation of the fan's depocenters.
\end{abstract}

Keywords: gravity tectonics, gravitational fold-and-thrust belts, Amazon Deep-sea Fan, Brazilian equatorial margin.

RESUMO. As seqüências marinhas da Bacia Foz do Amazonas são deformadas pela tectônica gravitacional, incluindo aquelas do Leque do Amazonas. As estruturas associadas ao colapso gravitacional, imageadas por sísmica multicanal 2D, foram formadas pelo deslizamento gravitacional da cobertura sedimentar sobre níveis basais móveis, induzido pela sobrecarga sedimentar e pelo gradiente do talude. 0 deslizamento gravitacional ocorreu ao longo de distintas superfícies de descolamento e, aparentemente, em diferentes estágios evolutivos da margem. Ao menos três níveis estratigráficos principais atuaram como superfícies de descolamento, em escala regional ou local. Cinturões de dobramento e cavalgamento em águas profundas são as estruturas mais notáveis deste arcabouço; sua geometria e complexidade variam ao longo da margem em reposta à variação lateral do desenvolvimento dos depocentros do Leque do Amazonas. Estas estruturas são mais complexas no Compartimento Noroeste onde os principais depocentros estão presentes, formando múltiplas frentes compressivas devido ao mais intenso encurtamento da cobertura sedimentar. No Compartimento Sudeste, o sistema é menos desenvolvido e se limita a um cinturão parcialmente inativo, caracterizado apenas por um par de falhas reversas ativas com menor impacto morfológico. Localmente, falhas normais lístricas antitéticas se ancoram sobre a superfície de descolamento mais superior, exercendo um controle estrutural sobre a segmentação dos depocentros do próprio leque.

Palavras-chave: tectônica gravitacional, cinturões de dobramento gravitacional, Leque Submarino do Amazonas, margem equatorial brasileira.

*Esta é uma contribuição do grupo de estudos GEOMARGEM - Geologia e Oceanografia de margens continentais passivas (http://www.geomargem.org).

${ }_{1}^{1}$ Programa de Pós-Graduação em Geologia e Geofísica Marinha, Departamento de Geologia, LAGEMAR, Instituto de Geociências/UFF, Av. General Milton Tavares de Souza, s/n, $4^{\circ}$ andar, Campus da Praia Vermelha, Gragoatá, 24210-346 Niterói, RJ, Brasil. Tel.: (21) 2629-5930/2629-5932; Fax: (21) 2629-5931 - E-mails: rperovano@gmail.com; cleverson@igeo.uff.br; erikafsa@gmail.com

2 Programa de Mestrado em Oceanografia, Faculdade de Oceanografia/UERJ, Rua São Francisco Xavier, 524, $4^{\circ}$ andar, Maracanã, 20550-900 Rio de Janeiro, RJ, Brasil. Tel.: (21) 2587-7838-E-mail: antonio.tadeu@pq.cnpq.br

3 Université des Sciences et Technologies de Lille I, U.F.R. des Sciences de la Terre, Cite Scientifique, Batiment SN5, UMR 8110, 59655 Villeneuve d’Ascq cedex, France

-E-mail: bruno.vendeville@univ-lille1.fr

${ }^{4}$ Laboratoire Evolution et Modélisation des Bassins Sédimentaires, Institut des Sciences de la Terre Paris (iSTeP) - CNRS UMR 7193, Université Pierre et Marie CurieParis 6. 4 place Jussieu - case 117, Tour 56-66, 5ème étage, 75252 Paris cedex 05 France - E-mail: christian.gorini@upmc.fr

5 Petróleo Brasileiro S.A. (Petrobras), Unidade de Negócios da Bahia, Av. Antonio Carlos Magalhães, 1113, $4^{\circ}$ andar, Pituba, 41825-903 Salvador, BA, Brasil. Tel.: (71) 3348-4117-E-mail: valterlene@petrobras.com.br 


\section{INTRODUÇÃo}

0 estudo da tectônica gravitacional (gravity tectonics) tem recebido especial atenção da comunidade científica nas últimas décadas, uma vez que importantes áreas potenciais e/ou produtoras de petróleo são estruturalmente afetadas por deformações induzidas por um nível basal móvel (e.g. Golfo do México, bacias da margem Leste Brasileira, Margem Oeste Africana, bacias do entorno Mediterrâneo). Uma série de estudos de caso e de modelagem física experimental contribuiu para a compreensão contemporânea da tectônica gravitacional, especialmente quando induzida por um nível basal evaporítico (e.g. Dahlen et al., 1984; Jenyon, 1986; Vendeville \& Cobbold, 1987, 1988; Cobbold et al., 1989; Worrall \& Snelson, 1989; Jackson \& Cramez, 1989; McClay, 1990; Cobbold \& Szatmari, 1991; Vendeville, 1991; Vendeville \& Jackson, 1992a, b; Duval et al., 1992; Jackson et al., 1994, 1995; Cobbold et al., 1995; Mohriak et al., 1995; Ge et al., 1997; Rowan et al., 1999; Rowan et al., 2000; Schultz-Ela, 2001; Koyi \& Vendeville, 2003; Rowan et al., 2004; Reis et al., 2005; Vendeville, 2005a, b; Hudec \& Jackson, 2007; Krézsek et al., 2007). No entanto, estudos sobre a modalidade de tectônica gravitacional envolvendo níveis superpressurizados ainda permanecem relativamente pouco numerosos (e.g. Bruce, 1973; Guimarães et al., 1989; Caldeira et al., 1991; Cohen \& McClay, 1996; Morley \& Guerin, 1996; Silva et al., 1999; Zalán, 1999; Wu \& Bally, 2000; Hooper et al., 2002; Rensbergen et al., 2003; Vendeville \& Gaullier, 2003; Rowan et al., 2004; Cobbold et al., 2004; Oliveira, 2005; Zalán, 2005; Mourgues \& Cobbold, 2006a, b; Sultan et al., 2007; Lecomte \& Vendeville, 2008).

Na Bacia da Foz do Amazonas, a literatura científica faz referências à ocorrência de feições deformacionais decorrentes de tectônica gravitacional induzida por um nível basal móvel constituído por argilas superpressurizadas (shale tectonics), que deforma as seqüências sedimentares marinhas da bacia, incluindo 0 Leque Submarino do Amazonas (Guimarães et al., 1989; Silva \& Rodarte, 1989; Silva et al., 1999; Zalán, 1999; Cobbold et al., 2004; Oliveira, 2005). Todavia, considerando que 0 Leque Submarino do Amazonas (a partir daqui referenciado como Leque do Amazonas) é um dos mais importantes leques turbidíticos em escala mundial, e que apresenta potencial para a exploração e explotação de hidrocarbonetos (gás e óleo), a compreensão do processo gravitacional na região é ainda insuficiente e parcial. Modelos estruturais distintos foram propostos para a representação do arcabouço da tectônica gravitacional na bacia, mas diversos parâmetros relacionados à tectônica ainda permanecem desconhecidos, tais como a natureza dos níveis basais de descolamento e a evolução espacial e temporal do sistema gravitacional.

Neste contexto, 0 objetivo deste trabalho é detalhar 0 arcabouço e a evolução estrutural da tectônica gravitacional na Bacia da Foz do Amazonas, e investigar a relação entre deformação e desenvolvimento dos principais depocentros da bacia.

\section{BASE DE DADOS E METODOLOGIA}

A metodologia da pesquisa baseia-se na aplicação de métodos complementares para o estudo da evolução estrutural da tectônica gravitacional na Bacia da Foz do Amazonas, através da análise estrutural e sismo-estratigráfica de dados sísmicos de reflexão multicanal 2D e de modelagem física experimental (modelos analógicos em escala). Para tal, utilizou-se cerca de 15.000 km de perfilagem sísmica multicanal 2D, que recobrem grande parte da bacia (Fig. 1). 0 conjunto de dados envolve a compilação de diferentes levantamentos sísmicos com penetração de sinal variando entre 10 e 13s e resolução vertical entre 5 e 10 m, compreendendo linhas sísmicas do "Projeto de Delimitação da Plataforma Continental Jurídica Brasileira (Projeto LEPLAC)", cedidos pela Secretaria Interministerial para os Recursos do Mar (SECIRM), e um conjunto de linhas sísmicas disponibilizadas pelas empresas FUGRO e GAIA.

Os dados regionais de batimetria utilizados na pesquisa são de natureza predita e resultam da compilação de dados de altimetria de satélite (ETOP02 - Smith \& Sandwell, 1997), e de dados de batimetria de alta resolução da porção superior do Leque do Amazonas compilados e cedidos pela Diretoria de Hidrografia e Navegação (DHN - Marinha do Brasil), a partir de dados do projeto LEPLAC (Petrobras), do Geophysical Data System (GEODAS) e do General Bathymetric Charts of the Oceans (GEBCO).

A interpretação estratigráfica e estrutural das seções sísmicas foi baseada na identificação e no mapeamento das principais estruturas do arcabouço tectônico, segundo os princípios gerais da estratigrafia sísmica e estudos de caso (e.g. Mitchum et al., 1977a, b; Morley \& Guerin, 1996; Silva et al., 1999; Wu \& Bally, 2000; Rowan et al., 2004). Posteriormente, para um melhor entendimento dos mecanismos controladores da tectônica gravitacional no Leque do Amazonas, foram confeccionados mapas de estruturas, mapas da morfologia das superfícies de décollement ou descolamento e mapas de isópacas da cobertura sedimentar sintectônica. A interpretação sismo-estratigráfica e a confecção dos mapas foram efetuadas utilizando a suite de programas Kingdom Suite ${ }^{\circledR} 8.0$. 


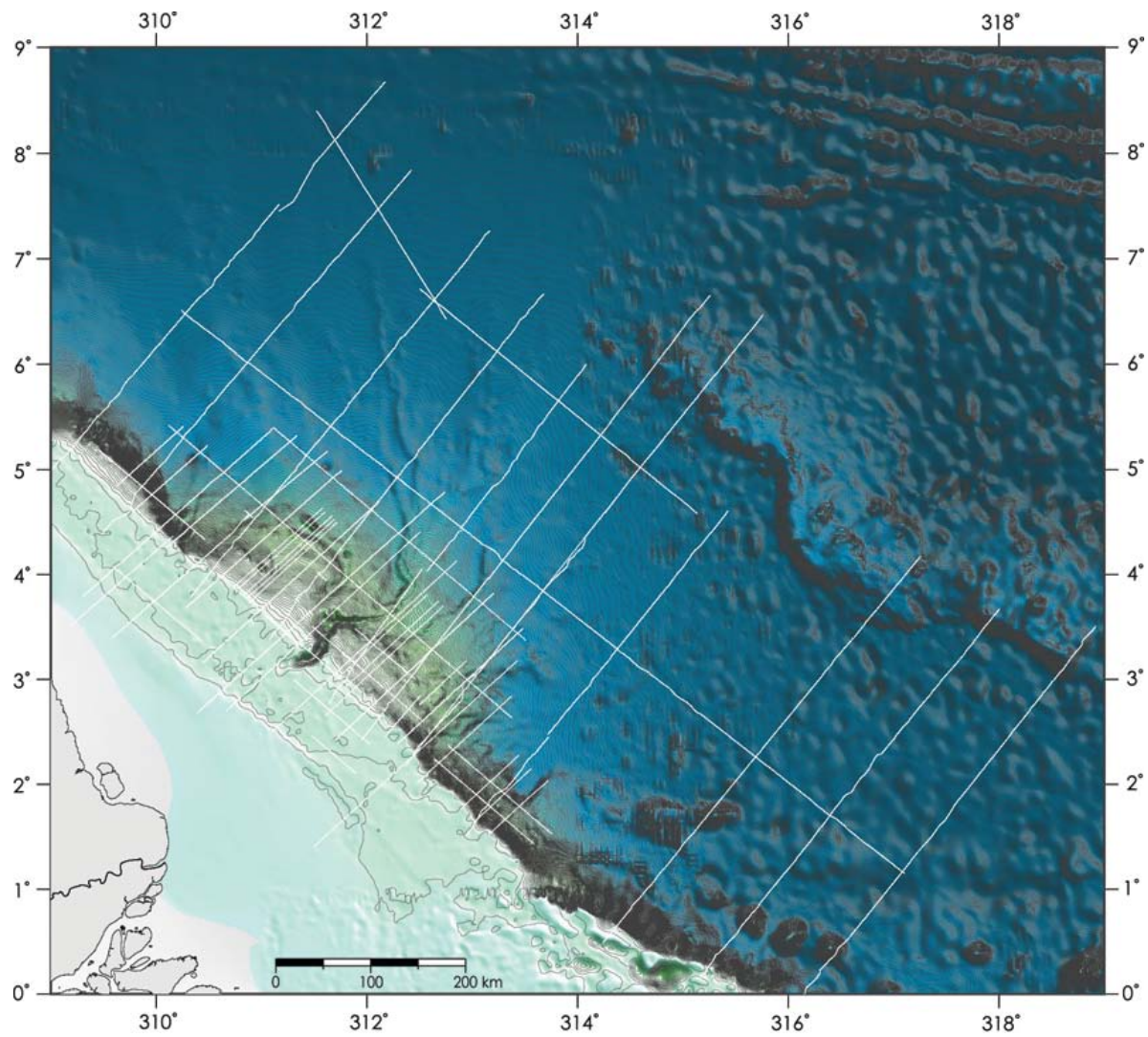

Figura 1 - Mapa batimétrico regional da Bacia da Foz do Amazonas com localização das linhas sísmicas utilizadas neste estudo. Dados batimétricos regionais do ETOP02 (Smith \& Sandwell, 1997) e locais, no Leque Superior e Médio do Amazonas, fornecidos pela Diretoria de Hidrografia e Navegação, DHN-Marinha do Brasil.

0 estudo inclui ainda a realização de modelos experimentais conduzidos no Laboratório de Modelagem Analógica da Université Lille 1, na França, que dispõe de um dispositivo que opera com injeção de fluidos à pressão controlada, capaz de simular 0 deslizamento gravitacional induzido pela superpressurização de níveis argilosos (Mourgues \& Cobbold, 2003; Lecomte \& Vendeville, 2008).

\section{CARACTERIZAÇÃO REGIONAL}

A margem equatorial brasileira representa um exemplo de margem passiva com uma longa história de movimentos transformantes (Azevedo, 1991; Matos, 1999, 2000). Este contexto cinemático resultou no desenvolvimento de uma série de bacias en échelon de direção geral NW-SE, de oeste para leste, as Bacias da Foz do Amazonas, Pará-Maranhão, Barreirinhas, Ceará e Potiguar (Fig. 2). Estas bacias são estruturalmente complexas, tendo sido afetadas por esforços de natureza transcorrente (wrench tectonics) durante o Barremiano Superior - Aptiano, cinematicamente relacionados à ativação das zonas de fratura oceânicas, principal- mente as de Romanche e de São Paulo (Azevedo, 1991; Matos, 1999, 2000).

A Bacia da Foz do Amazonas, área de estudos, é a mais extensa dentre as bacias da margem equatorial brasileira, localizada na sua porção noroeste (Fig. 2). Seus limites coincidem, a noroeste, com o Platô de Demerara e, a sudeste, com a llha de Santana (Bacia do Pará-Maranhão). Apenas a área submersa da bacia totaliza aproximadamente 360.000 km² (Brandão \& Feijó, 1994; Silva et al., 1999).

Silva et al. (1999), baseados na análise integrada de 26 poços de sondagem e interpretação sísmica, propuseram uma subdivisão crono-estratigráfica simplificada para a Bacia da Foz do Amazonas, que foi adotada no presente trabalho. Seis megasseqüências principais foram identificadas, sendo uma megasseqüência correspondente à fase rifte e cinco megasseqüências correspondentes à fase drifte da bacia.

A fase rifte (Cretáceo Inferior), encontrada normalmente preenchendo meio-grábens, é formada basicamente por um pacote vulcano-sedimentar constituído de rochas ígneas basálticas intercaladas com sedimentos arenosos de origem continental; e um 


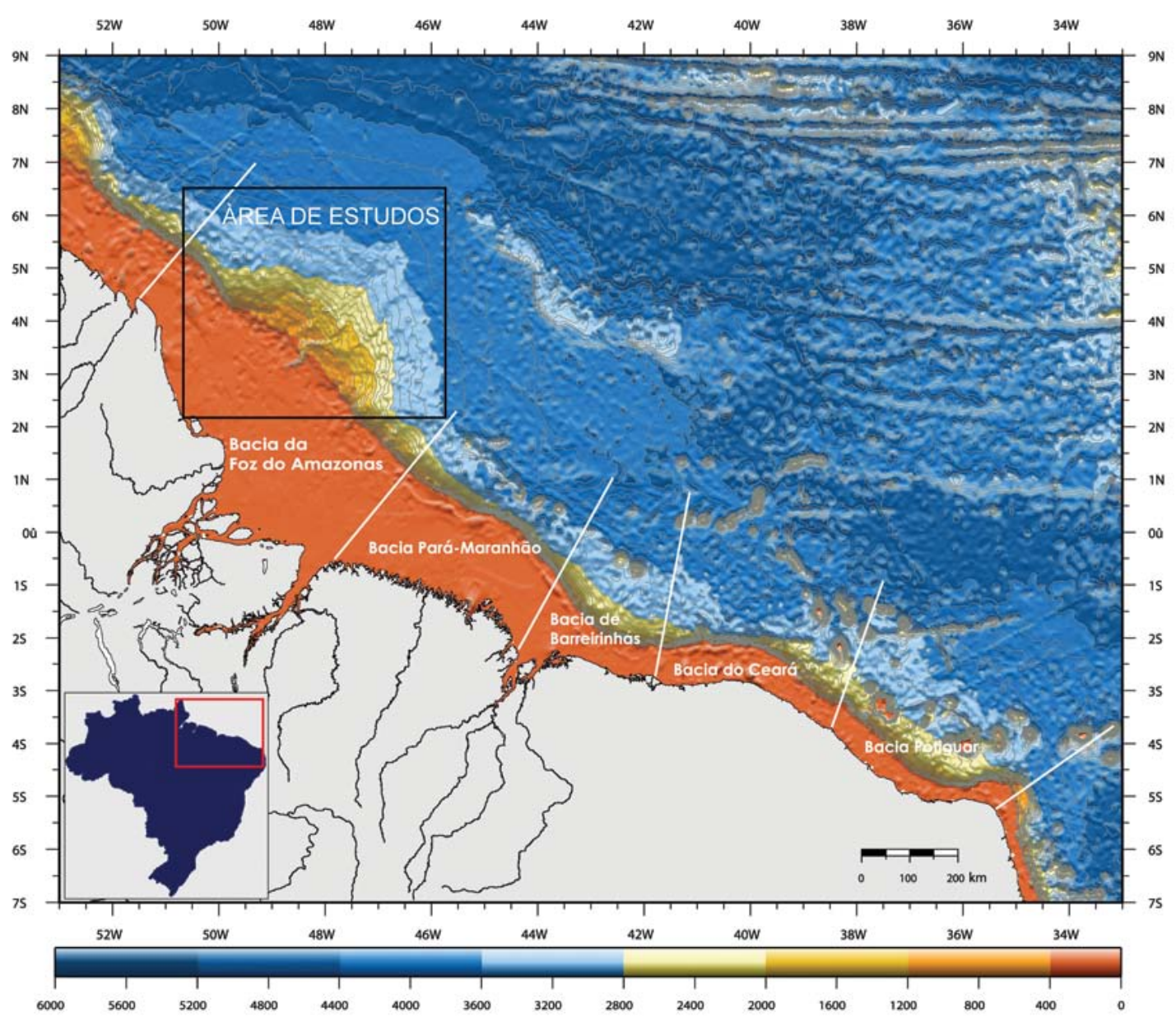

Figura 2 - Mapa regional da margem equatorial brasileira com a localização da área de estudos (dados batimétricos regionais do ETOP02, Smith \& Sandwell, 1997).

pacote formado em um ambiente fluvio-deltaico lacustre, constituído de folhelhos cinzentos intercalados com arenitos finos (Brandão \& Feijó, 1994; Figueiredo et al., 2007).

As cinco megasseqüências drifte correspondem aos seguintes intervalos de tempo, respectivamente: Cretáceo SuperiorPaleoceno (100-65 Ma), Paleoceno-Eoceno (65-40 Ma), Oligoceno (40-25 Ma), Mioceno Inferior-Médio (25-10 Ma) e Mioceno Superior ao Recente (10-0 Ma) (Brandão \& Feijó, 1994; Silva et al., 1999; Figueiredo et al., 2007). A primeira seqüência drifte (Cretáceo Superior-Paleoceno) é constituída principalmente por arenitos finos, folhelhos e siltitos cinza de ambiente fluviodeltáico, nerítico e batial, interpretada como uma unidade transgressiva (Brandão \& Feijó, 1994).

No intervalo de tempo entre o Paleoceno e o Mioceno Médio foi instalada, na região do atual Leque do Amazonas, uma plataforma estável compreendendo em sua maior parte, um ambiente de plataforma carbonática espessa (Brandão \& Feijó, 1994;
Figueiredo et al., 2007). A megasseqüência depositada entre 0 Paleoceno e o Eoceno possui uma espessura média de $1000 \mathrm{~m}$ contra 200 m da megasseqüência oligocênica e 1500 m da megasseqüência que abrange o Mioceno Inferior e o Médio (Silva et al., 1999). A despeito da grande espessura sedimentar da plataforma, a bacia profunda apresenta-se menos espessa (1000 m) (Silva et al., 1999). Ainda entre o Paleoceno e o Mioceno Médio, na porção central da bacia, a borda da plataforma apresenta uma direção diferente da orientação NW-SE observada nos dias atuais, apresentando uma morfologia côncava, que corresponde ao limite sudoeste dos principais depocentros constituintes do Leque do Amazonas. Os sedimentos próximos a esta porção apresentamse deformados por falhas lístricas e falhas de empurrão (Silva et al., 1999).

A última megasseqüência, depositada do Mioceno Superior ao Recente, possui um caráter progradacional (Brandão \& Feijó, 1994; Figueiredo et al., 2007), e compõe a essência do Leque do 
Amazonas. A formação do Leque do Amazonas teve início a partir de fases de aumento da taxa de soerguimento da Cadeia Andina no Mioceno Médio-Superior (11.8-11,3 Ma, Figueiredo et al., 2009), que estabeleceu 0 curso do Rio Amazonas na direção do Oceano Atlântico (Maslin \& Mikkelsen, 1997; Flood \& Piper, 1997; Rimington et al., 2000; Gregory-Wodzicki, 2000; Lopez, 2001; Cobbold et al., 2004; Maslin et al., 2005; Figueiredo et al., 2009). Os sucessivos níveis de mar baixo responsáveis pela deposição do leque fizeram com que a enorme carga sedimentar trazida pelo rio fosse diretamente depositada na borda da plataforma e no talude continental (Maslin \& Mikkelsen, 1997; Rimington et al., 2000; Lopez, 2001).

Estratigraficamente, o Leque do Amazonas correspondente à última das 6 megasseqüências que compõem a Bacia da Foz do Amazonas (Silva \& Rodarte, 1989; Silva et al., 1999) composta por formações de idade Mioceno Superior-Recente agrupadas no chamado Grupo Pará (Brandão \& Feijó, 1994; Silva et al., 1999). Folhelhos e argilitos depositados no talude e na bacia profunda, preferencialmente na região do Leque do Amazonas, associados às poucas camadas de arenitos finos depositados sob a ação de correntes de turbidez, compõem a chamada Formação Orange. A Formação Orange foi identificada por vários autores como num estado de superpressurização de fluidos, que poderia ser a origem da mobilidade indutora da tectônica gravitacional que afeta as seqüências sobrepostas (Franke, 1975; Bruno, 1987; Brandão \& Feijó, 1994; Silva et al., 1999).

As megasseqüências marinhas (Cretáceo Superior-Recente) apresentam-se deformadas pela tectônica gravitacional. TrabaIhos pretéritos relataram a presença de "domos de lama" em larga escala na área (Bruno, 1987) que posteriormente, com a sofisticação das técnicas de processamento sísmico, em sua maioria foram reinterpretados como falhas reversas agrupadas em frentes compressivas (Silva et al., 1999; Cobbold et al., 2004; Oliveira, 2005).

Silva et al. (1999) identificaram as estruturas da Bacia da Foz do Amazonas, decorrentes do espalhamento gravitacional da cobertura sedimentar ao longo de dois níveis de décollement de idades distintas: falhas normais lístricas proximais na região da plataforma continental mecanicamente associadas a uma superfície de décollement mais antiga correspondente ao Albiano (cerca de $100 \mathrm{Ma}$ ); enquanto que famílias de falhas normais lístricas na região do talude e falhas de empurrão mais distais constituem membros estruturais induzidos por uma superfície de décollement mais jovem localizada no limite Cretáceo-Terciário (cerca de $65 \mathrm{Ma}$ ). Neste caso, a deformação afeta somente 0 prisma progradante sobrejacente. Os autores também associam mecanicamente a zona compressiva à presença da Zona de Fratura de São Paulo, que teria atuado como barreira morfológica impedindo a translação gravitacional do pacote sedimentar, e desse modo, favorecido a formação de um campo compressional.

Mais recentemente, Cobbold et al. (2004) e Oliveira (2005) propuseram uma compartimentação estrutural para a tectônica gravitacional da bacia, constituída por um compartimento a sudeste e outro a noroeste, de diferentes dimensões e complexidade.

\section{RESULTADOS}

Neste trabalho, foram mapeadas e detalhadas as feições estruturais conhecidas da tectônica gravitacional na Bacia da Foz do Amazonas (Silva et al., 1999; Cobbold et al., 2004; Oliveira, 2005). A análise estrutural efetuada nos traz uma série de novas informações sobre 0 arcabouço estrutural e a compreensão da tectônica gravitacional na Bacia da Foz do Amazonas. Os resultados apresentados a seguir se articulam em torno da análise estrutural baseada em interpretação sísmica, na confecção de mapas de isópacas e na realização de modelagem física experimental (modelos analógicos em escala) (Da Silva, 2008).

\section{Análise sísmica: 0 arcabouço estrutural da tectônica gravitacional na Bacia da Foz do Amazonas}

A base de dados disponível (Fig. 1) permitiu o mapeamento de inúmeras falhas normais, na região da plataforma e talude da Bacia da Foz do Amazonas, conectadas, via superfície basal de descolamento a conjuntos de falhas reversas distais em águas profundas. Este conjunto de estruturas decorrentes do colapso gravitacional das seqüências marinhas da bacia envolve uma área deformada que chega a atingir aproximadamente $191 \mathrm{~km}$ de largura máxima no sentido plataforma-bacia, e cerca de 300 km de comprimento, resultando numa área total deformada de aproximadamente $45.000 \mathrm{~km}^{2}$ (Fig. 3). Tais estruturas distribuemse segundo uma zonação estrutural característica: um domínio extensivo proximal, onde predominam falhas normais lístricas sintéticas e antitéticas; e um domínio compressivo distal, caracterizado essencialmente pela presença de falhas de cavalgamento e antiformes associados (Fig. 3). Foram identificadas e mapeadas na conceitualmente chamada zona de translação intermediária, estruturas antiformes, rollovers e dobras, que deformam a cobertura sedimentar, indicando a presença de esforços de natureza compressiva em função da acomodação do colapso gravitacional. Desse modo, baseado na semelhança estrutural e na inexistência de características singulares, as estruturas com- 


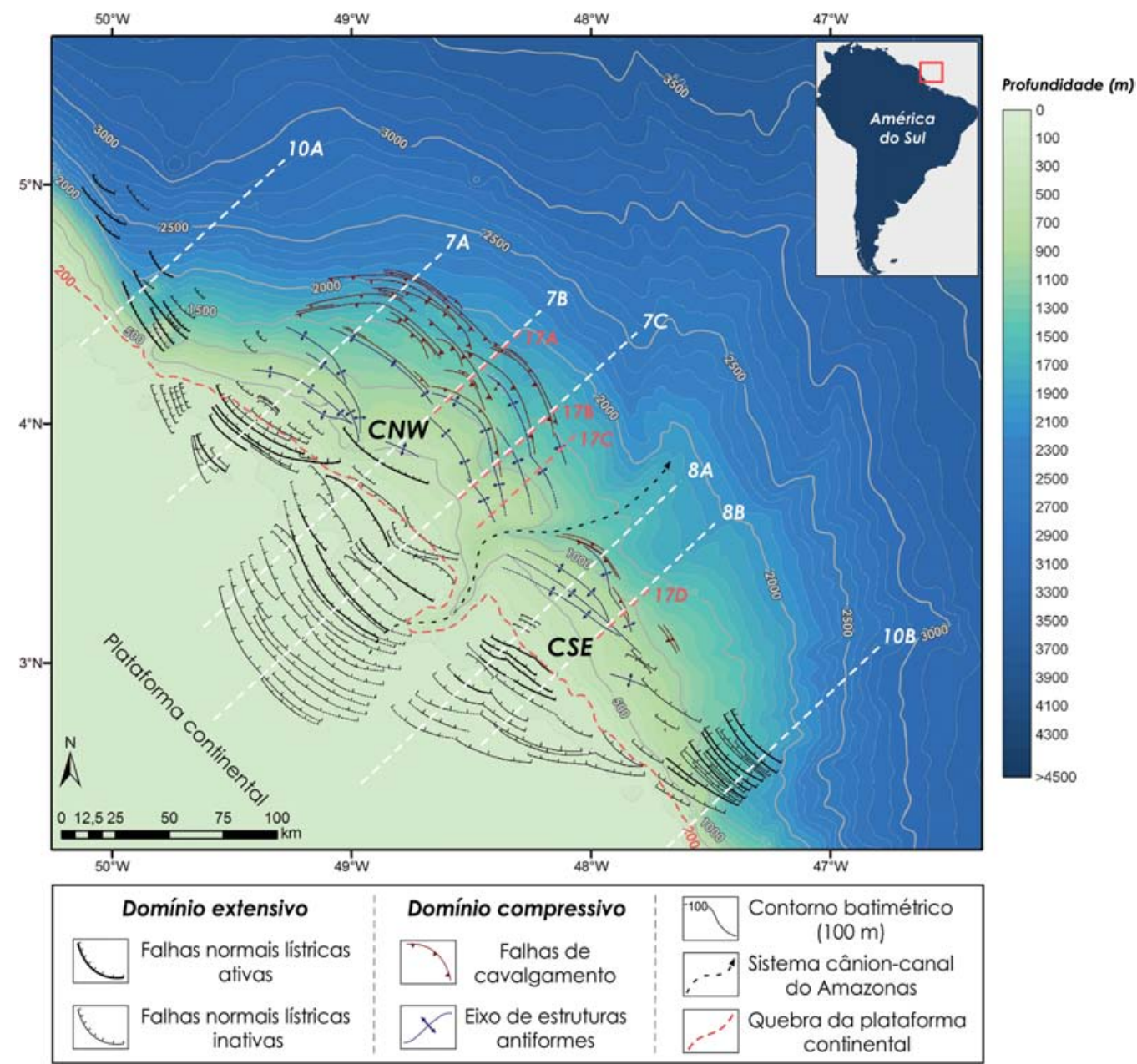

Figura 3 - Mapa das estruturas da tectônica gravitacional na Bacia da Foz do Amazonas. CNW = Compartimento Noroeste e CSE = Compartimento Sudeste de Oliveira (2005).

pressivas mapeadas nesta região foram integradas ao chamado domínio compressivo.

0 domínio extensivo distribui-se desde a região da plataforma continental estendendo-se a profundidades de até cerca de $750 \mathrm{~m}$ no talude (Fig. 3). 0 domínio é caracterizado pela presença predominante de falhas normais lístricas sintéticas, que possuem mergulho em direção à bacia, e, em menor número, por falhas antitéticas, anticlinais em rollovers e cunhas sedimentares sintectônicas (expanding stratigraphic wedges) (Fig. 4). As faIhas normais lístricas apresentam uma distância média entre si de aproximadamente 3-8 km, e uma extensão de linha de falha de até cerca de $80 \mathrm{~km}$ (Fig. 3). De modo geral, as falhas encontram-se soterradas na plataforma continental (Figs. 3 e 4a), mas algumas atingem a superfície na região de borda da plataforma, formando escarpas de falha de até 150-180 metros de desnível morfológico
(Figs. 3 e 4b). A carência de dados na região da plataforma continental dificultou sobremaneira o mapeamento estrutural neste domínio, em função dos grandes espaçamentos entre os perfis sísmicos disponíveis.

A interpretação sísmica mostra ainda que 0 deslizamento da seção marinha da bacia ocorreu ao longo de distintas superfícies de descolamento (Fig. 5). Inúmeras falhas lístricas do domínio extensivo, sobretudo aquelas presentes na região da plataforma continental, se ancoram claramente sobre uma superfície de descolamento mais antiga, localizada na base da seqüência marinha da bacia, diretamente sobre 0 topo da seqüência sin-rifte - aqui chamada de superfície Azul (Fig. 5b). Estratigraficamente, esta superfície corresponde provavelmente à base da Megasseqüência Cretáceo Superior (100-65 Ma), baseado na correlação com os dados sísmicos publicados de Silva et al. (1999). A deformação 

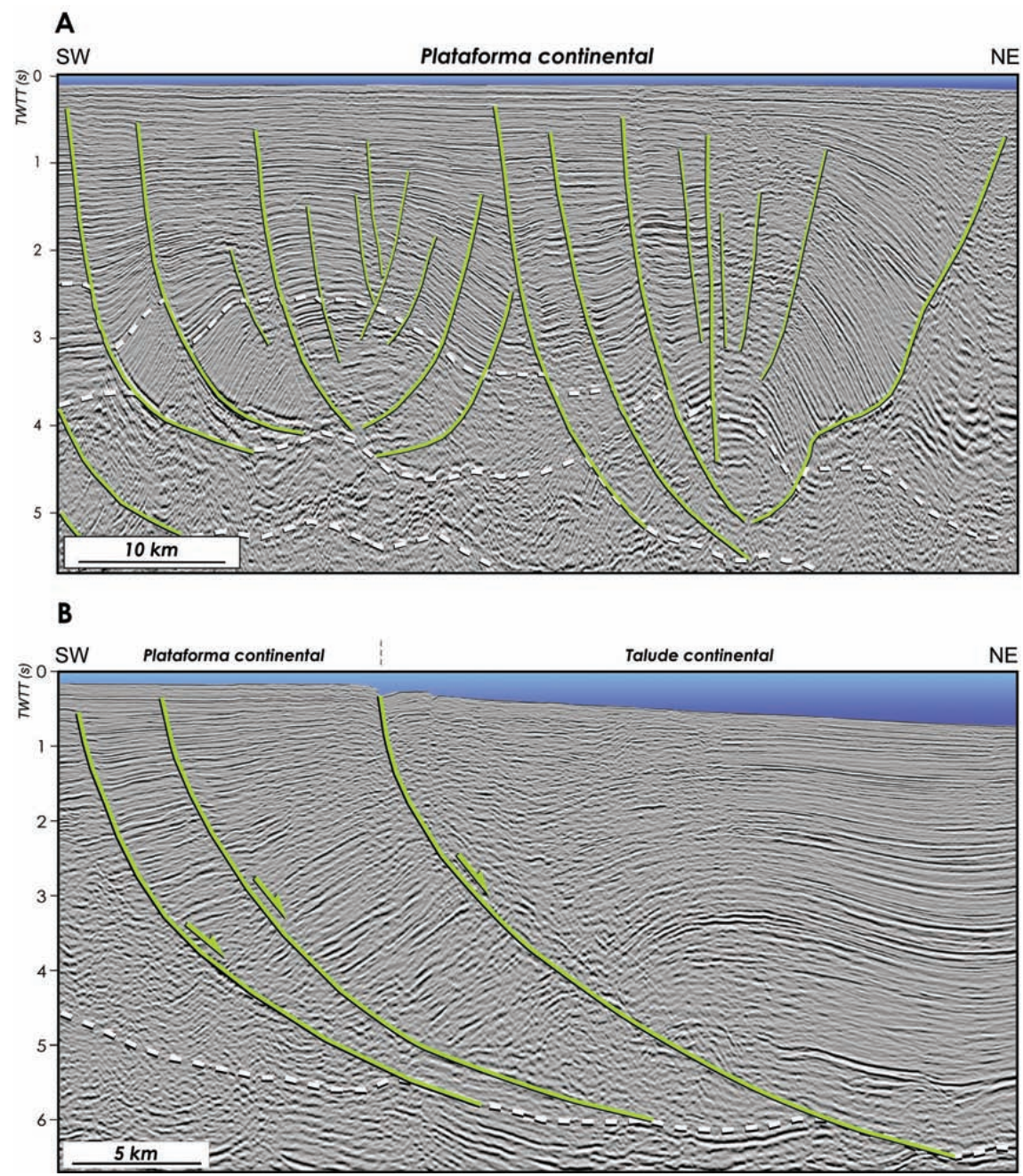

Figura 4 - Perfis sísmicos (profundidade em tempo) ilustrando as falhas normais lístricas sintéticas e antitéticas do domínio extensivo da tectônica gravitacional da Bacia da Foz do Amazonas, ancoradas sobre superfícies de descolamento basais (linhas tracejadas).

da seção deslizada sobre o nível de descolamento Azul se caracteriza por falhas normais lístricas na região da plataforma continental interna que, de modo geral, propagam-se para o topo da coluna sedimentar, sem contudo atingir o fundo oceânico (Fig. 5), e estão ancoradas sobre a morfologia residual resultante dos estágios pretéritos da evolução tectônica do rifteamento. Entretanto, a maior parte das estruturas extensivas localizadas na plataforma continental e no talude superior, incluindo todas as falhas lístricas ativas, estão ancoradas sobre a superfície intermediária de descolamento de expressão regional, aqui chamada de superfície Verde (Fig. 5b). Esta superfície corresponde provavelmente à base da Megasseqüência Paleoceno-Eoceno (65-40 Ma) de Silva et al. (1999).
0 domínio compressivo é constituído por uma conjunção de falhas reversas com mergulho sistemático em direção ao continente e estruturas antiformes (Fig. 3). Tais estruturas se agrupam em frentes compressivas de dobramentos e cavalgamentos (foldand-thrust belts) de orientação NW-SE (Figs. 5 e 6), que podem chegar a cerca de $90 \mathrm{~km}$ de largura em algumas regiões, afetando o fundo submarino até aproximadamente $2100 \mathrm{~m}$ de profundidade (Figs. 3 e 6). 0 comprimento de linha das falhas de cavalgamento situa-se entre cerca de 20-60 km, enquanto a distância média entre elas situa-se entre 6-10 km (Fig. 3). A maior parte das falhas, principalmente as mais próximas à plataforma, não se propaga para as seqüências sedimentares sobrepostas, formando paleo-cinturões de dobramentos e cavalgamentos soterrados na 


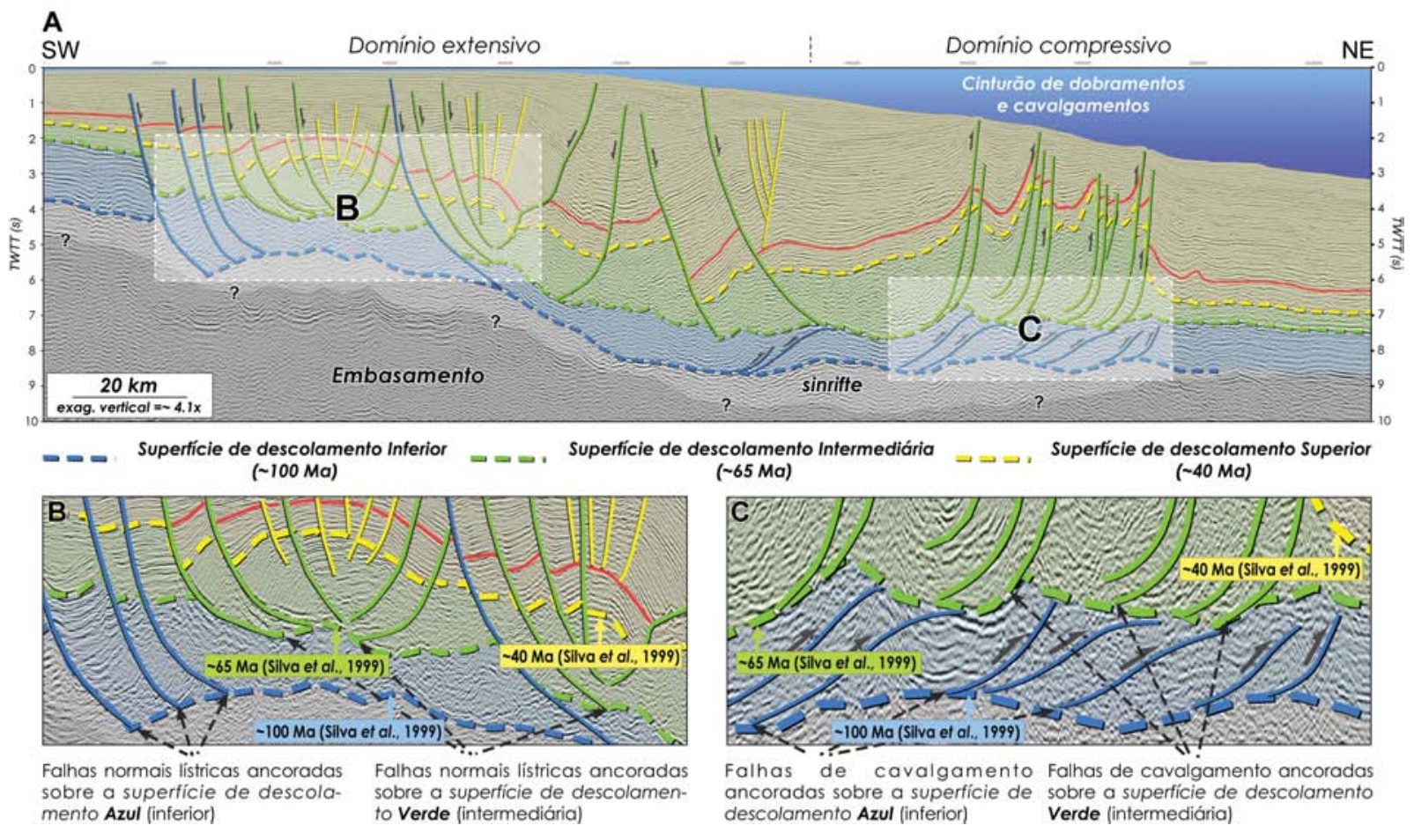

Figura 5 - (a) Perfil sísmico (em tempo) ilustrando o ancoramento das estruturas da tectônica gravitacional sobre três níveis de descolamento distintos na Bacia da Foz do Amazonas: Superfície de descolamento Azul (horizontes Albiano de 100 Ma segundo Silva et al., 1999), Superfície de descolamento Verde (horizontes de $\sim 65 \mathrm{Ma}$, localizado no limite Cretáceo-Terciário segundo Silva et al., 1999) e Superfície de descolamento Amarelo (horizontes Eoceno Médio de $\sim 40 \mathrm{Ma}$, inferido através de correlação com dados sísmicos publicados de Silva et al., 1999). (b) Detalhe da seção sísmica mostrando o ancoramento de falhas normais lístricas em diferentes superfícies de descolamento. (c) Detalhe da seção sísmica mostrando o ancoramento de falhas reversas em diferentes superfícies de descolamento.

região do talude. Ao contrário, quando aflorantes, as falhas podem afetar significativamente a morfologia do fundo submarino, formando altos e/ou escarpas de falha de até centenas de metros de desnível morfológico (Figs. 5 e 6), constituindo os acidentes morfológicos mais significativos em toda a escala do Leque do Amazonas (escarpas de falha de até cerca de $500 \mathrm{~m}$ de altura, Fig. $6 b)$, a partir dos quais processos remobilização sedimentar podem transferir massas e fluxos sedimentares para porções mais distais da margem continental (Araújo, 2008; Reis et al., 2008; Araújo et al., 2009; Reis et al., no prelo).

Esses altos estruturais delimitam ainda uma série de pequenas bacias confinadas e topograficamente elevadas (piggyback basins). A sismo-estratigrafia dessas mini-bacias mostra unidades sedimentares basais inclinadas (estratos subhorizontalizados com mergulho em direção ao continente) e unidades superficiais pouco ou não deformadas. A configuração das unidades sedimentares atesta a natureza sintectônica das minibaciais, cuja evolução se dá no contexto compressivo de imbricamento das falhas reversas (Fig. 6a).

Os principais cinturões de cavalgamento que deformam grande parte das seqüências marinhas da bacia, incluindo as seqüências que compõem o Leque do Amazonas, estão ancorados sobre a superfície de descolamento intermediária (superfície Verde, Figs. 5a e 5c). 0 estilo estrutural e a geometria desses cinturões variam lateralmente e refletem particularidades do desenvolvimento dos dois principais compartimentos estruturais da Bacia da Foz do Amazonas: o Compartimento Noroeste (NW) e 0 Compartimento Sudeste (SE) (Fig. 3).

0 Compartimento $\mathrm{NW}$ representa o maior compartimento estrutural, correspondendo a cerca de 2/3 da área total do sistema gravitacional do Leque do Amazonas. Este compartimento é estruturalmente mais complexo e mais amplo $\left(\sim 27.000 \mathrm{~km}^{2}\right)$, afetando a província do Leque Superior do Amazonas até profundidades entre 1600-2100 m (Fig. 3). A maior complexidade do sistema neste compartimento é exemplificada por uma série de estruturas antiformes e por imbricamentos de falhas de empurrão, em sua maioria ativa, que se sucedem em direção à bacia profunda (Fig. 3). Este conjunto de estruturas antiformes e de falhas de cavalgamento (parcialmente superpostas) forma os amplos cinturões gravitacionais compressivos (fold-and-thrust belts) de cerca de até 60-90 km de largura, que caracterizam 0 Compartimento NW (Figs. 5 e 7). Em contraste, a estruturação 

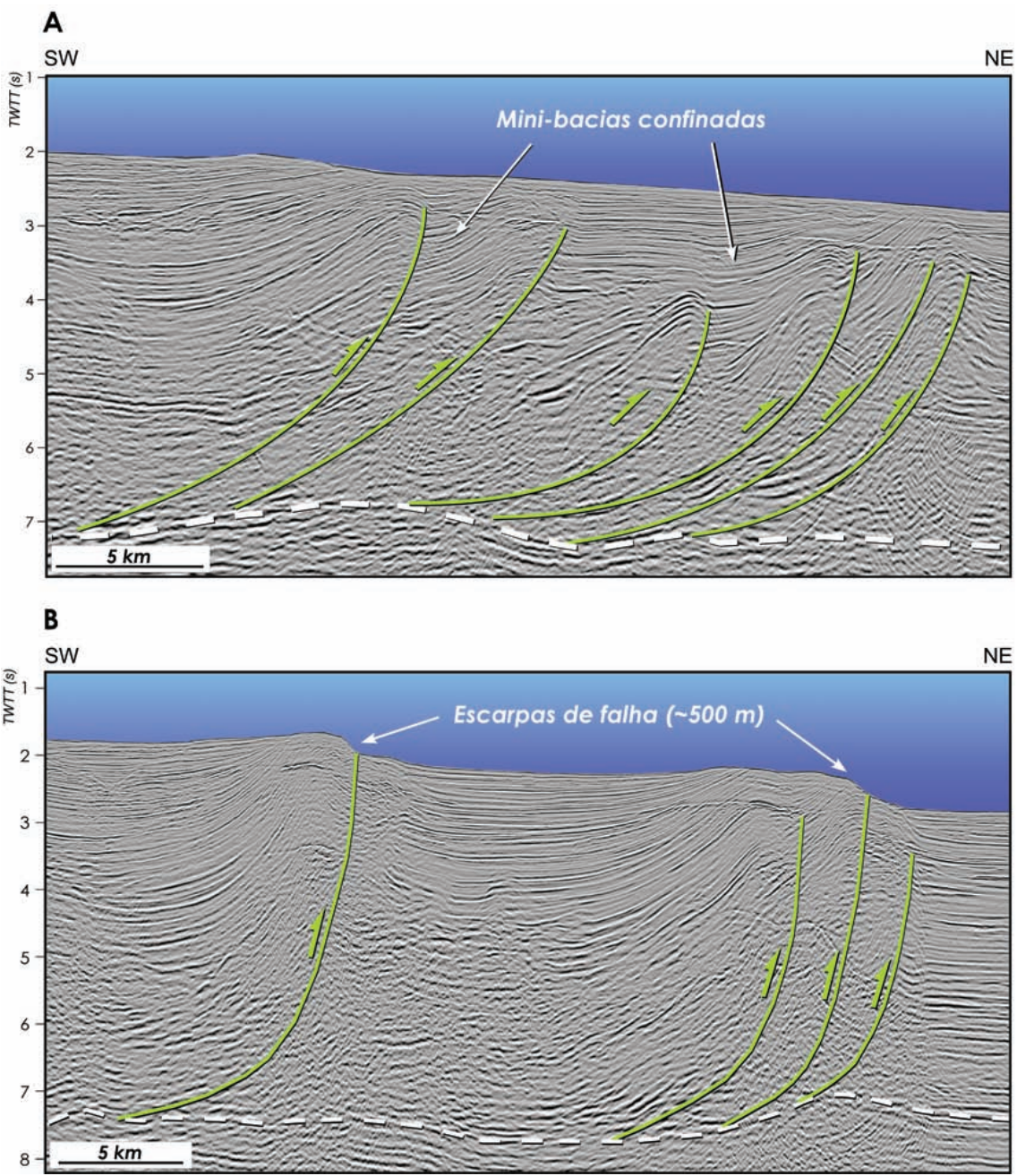

Figura 6 - Perfis sísmicos (em tempo) ilustrando as falhas reversas do domínio compressivo da tectônica gravitacional da Bacia da Foz do Amazonas, ancoradas sobre superfícies de descolamento basais (linhas tracejadas).

no Compartimento SE é relativamente mais simples. 0 Compartimento SE é significativamente mais restrito em área que 0 Compartimento NW $\left(\sim 11.500 \mathrm{~km}^{2}\right)$, compreendendo apenas a porção mais proximal da margem, até cerca de $1300 \mathrm{~m}$ de profundidade (Fig. 3). A menor complexidade relativa do sistema é ilustrada pela presença de um único cinturão compressivo ativo isolado, de menor expressão morfológica, que se estende até a profundidade de cerca de $1400 \mathrm{~m}$ de lâmina d'água (Fig. 3), evidenciando um menor encurtamento relativo da seção geológica sobreposta. Na verdade, a maior parte das estruturas compressivas observadas neste compartimento é expressa por um imbricamento de unidades estruturais compressivas (imbricate thrust sheets), que formam um cinturão de dobramento parcialmente inativo (soterrado). A deformação ativa é representada por um par de falhas reversas, que tende apenas a soerguer o fundo submarino, sem a formação de escarpas de falha como as do cinturão compressivo do Compartimento NW (Fig. 8).

0 mapeamento estrutural revelou ainda um cinturão compressivo contínuo e soterrado em posição distal, formado por imbricamentos de falhas de empurrão inativas, que se descola sobre a superfície de décollement inferior (superfície Azul). Este cinturão, mal imageado sismicamente, ocorre na parte central da bacia e apresenta um arranjo estrutural bastante complexo, formado por falhas, rampas de cavalgamento ( ramp-flat structures), evidenciando um alto grau relativo de encurtamento da seção (Figs. 5c, 7 e 8). 0 cinturão apresenta uma espessura contínua de cerca de 1,5-2,5 km, para uma velocidade sísmica intervalar estimada em $3000 \mathrm{~m} / \mathrm{s}$. A insuficiência de recobrimento e resolução sísmica 


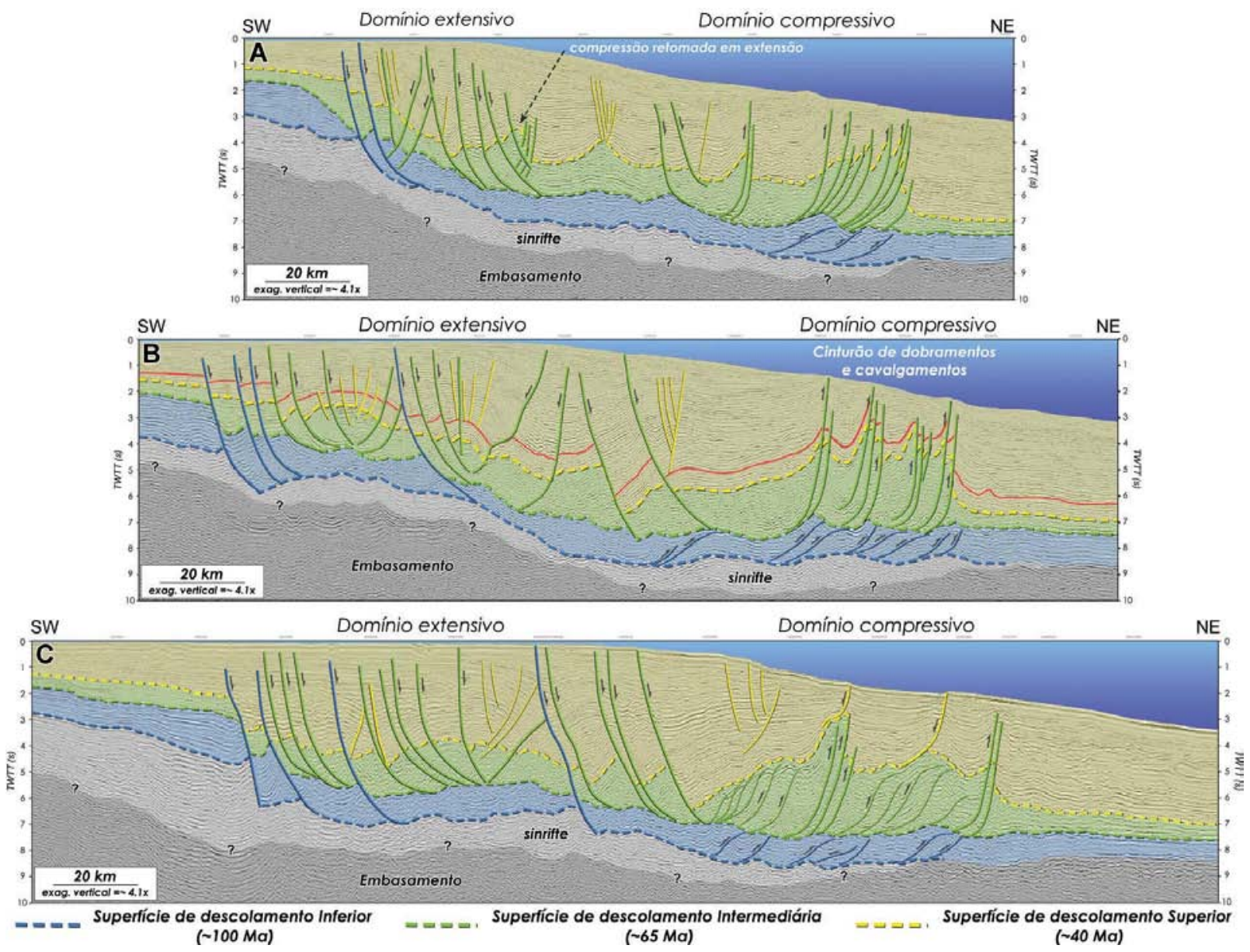

Figura 7 - Linhas sísmicas (em tempo) ao longo do Compartimento Noroeste da Bacia da Foz do Amazonas, ilustrando as variações do arcabouço estrutural da tectônica gravitacional na área. A linha vermelha representa a base da sucessão estratigráfica do Leque Submarino do Amazonas. As linhas pontilhadas representam: a Superfície de descolamento Azul (horizontes Albiano de 100 Ma segundo Silva et al., 1999), a Superfície de descolamento Verde (horizontes de 65 Ma, localizado no limite Cretáceo-Terciário segundo Silva et al., 1999) e a Superfície de descolamento Amarelo (horizontes Eoceno Médio de 40 Ma, inferido através de correlação com dados sísmicos publicados de Silva et al., 1999).

dos dados dificulta sobremaneira o mapeamento destas feições, e se configura como um desafio para a compreensão do que se apresenta como a mais antigo cinturão de colapso gravitacional da Bacia da Foz do Amazonas.

Eventos deformacionais mais recentes também ocorrem induzidos por um nível de descolamento mais superficial (superior) - aqui denominado superfície Amarela (Figs. 5, 7 e 8). Esta superfície parece corresponder à base da Megasseqüência Oligoceno (40-25 Ma) de Silva et al. (1999). A observação do arcabouço estrutural regional mostra que a superfície estratigráfica Amarela é regionalmente deformada nos domínios extensivos e compressivos da tectônica gravitacional da bacia. Contudo, esta superfície parece funcionar claramente como nível de descolamento mais recente em algumas regiões. Pode-se, por exemplo, observar a existência de falhas lístricas antitéticas ancoradas sobre a superfície Amarela se desenvolvendo nas regiões entre os domínios extensivos e compressivos da bacia, na região do Leque do Amazonas (Fig. 9). Além disso, esta superfície parece funcionar como nível de descolamento basal nos extremos noroeste e sudeste da bacia, onde a seção sedimentar apresenta menor espessura em relação à região de domínio do Leque do Amazonas (de cerca de 5 s no leque para cerca de 2-3s nos extremos sudeste e noroeste da bacia) (Fig. 10). Neste caso, observamos: (a) o desenvolvimento de falhas normais lístricas se descolando sobre a superfície Amarela, mas presentes somente na região de base do talude continental, não havendo estruturas relacionadas a este evento reconhecíveis na plataforma continental; e, (b) não há evidências de cinturões de dobramento e cavalgamento 

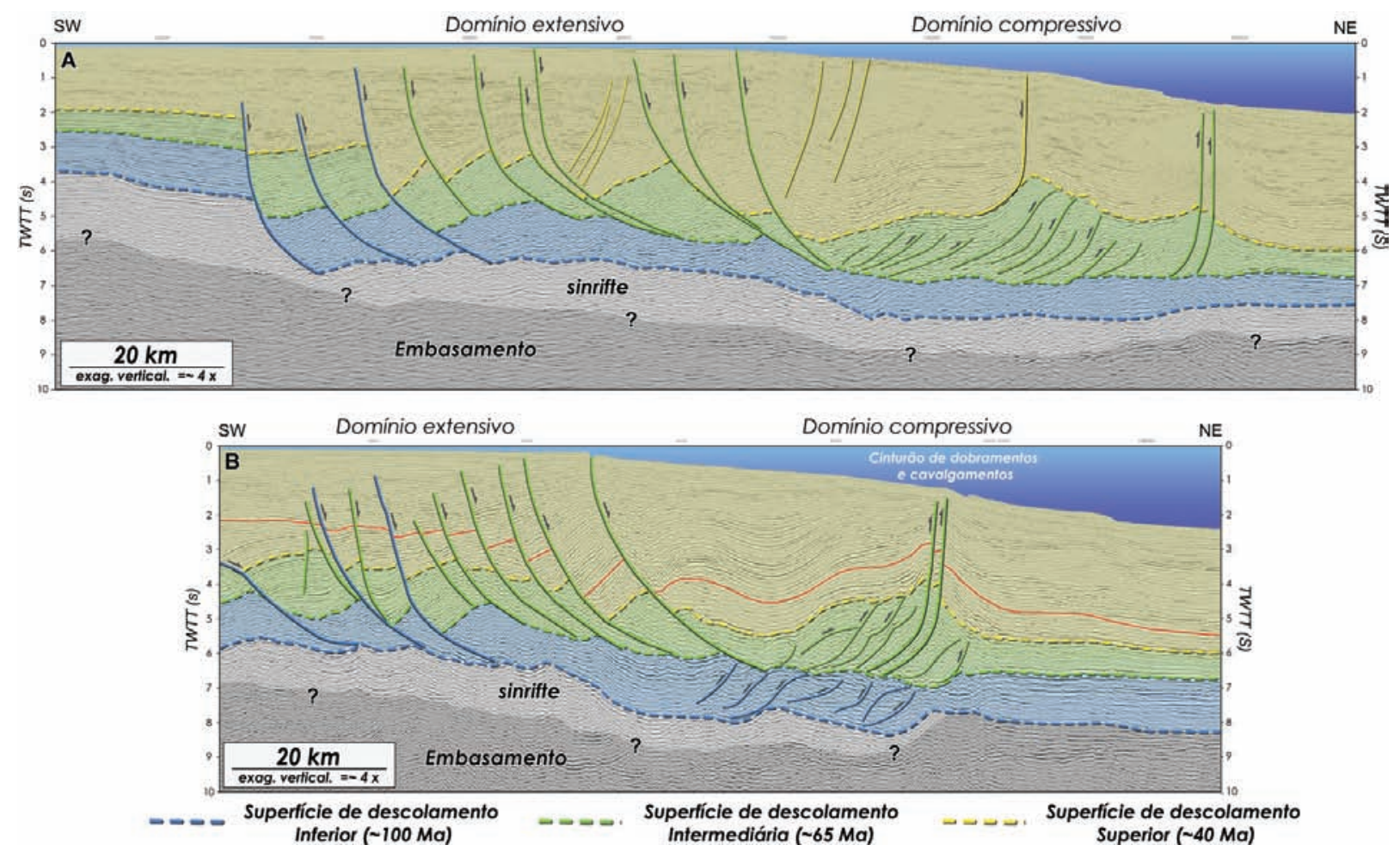

Figura 8 - Linhas sísmicas (em tempo) ao longo do Compartimento Sudeste da Bacia da Foz do Amazonas, ilustrando as variações do arcabouço estrutural da tectônica gravitacional na área. A linha vermelha representa a base da sucessão estratigráfica do Leque Submarino do Amazonas. As linhas pontilhadas representam: a Superfície de descolamento Azul (horizontes Albiano de 100 Ma segundo Silva et al., 1999), a Superfície de descolamento Verde (horizontes de 65 Ma, localizado no limite Cretáceo-Terciário segundo Silva et al., 1999) e a Superfície de descolamento Amarelo (horizontes Eoceno Médio de 40 Ma, inferido através de correlação com dados sísmicos publicados de Silva et al., 1999).

distais descolando-se sobre o nível Amarelo (Fig. 10). A ausência de feições de encurtamento distal (no nível de resolução dos dados sísmicos) sugere um grau de encurtamento bastante incipiente da seção geológica. Além disso, embora no extremo sudeste da bacia, a seção sedimentar que desliza sobre a superfície Amarela sofra visível rotação ao longo das falhas lístricas proximais (Fig. 10b), no extremo noroeste da bacia a seção "deslizada" apresenta uma série de falhamentos normais de rejeito pouco significativo e não apresenta feições rotacionais visíveis (Fig. 10a).

\section{Mapas de isópacas}

A elaboração de uma série de mapas de isópacas das seqüências da Bacia da Foz do Amazonas que deslizam sobre as diferentes superfícies de descolamento reconhecidas (superfícies Azul, Verde e Amarela) permitiram investigar a interação entre a zonação estrutural e a deposição sedimentar na bacia. 0 mapa de isópacas entre a superfície Verde e o fundo submarino detalha a distribuição espacial das seqüências sedimentares da bacia e revelam os principais depocentros já anteriormente mapeados por Oliveira (2005), chamados de depocentros D1 e D2 (Fig. 11). Os mapas de isópacas ilustram o espessamento proximal das seqüências sedimentares na região de borda de plataforma e Leque Superior do Amazonas, a individualização dos depocentros D1 e D2, e ressaltam ainda a reentrância da plataforma carbonática de idade Paleoceno-Mioceno Médio (Silva et al., 1999). Além disso, 0 sistema de deformação gravitacional (falhas normais e reversas distais) se desenvolve espacialmente associado aos depocentros da bacia. Os mapas revelam claramente que 0 Compartimento NW corresponde à área que constitui o depocentro D1, de cerca de $190 \mathrm{~km}$ de largura, e que apresenta ainda valores máximos de espessura sedimentar; enquanto o Compartimento SE corresponde à área do depocentro D2, de cerca de $100 \mathrm{~km}$ de largura, de dimensão mais restrita e menor espessura sedimentar (Fig. 11).

Os mapas mostram ainda que as falhas lístricas ativas do domínio extensivo estão localizadas na região na qual se tem os valores máximos de espessura sedimentar dos depocentros D1 e D2, onde formam escarpamentos geralmente alinhados ao longo dos depocentros. 0 caráter sinsedimentares destas falhas parece favorecer o próprio desenvolvimento do depocentro, através do 

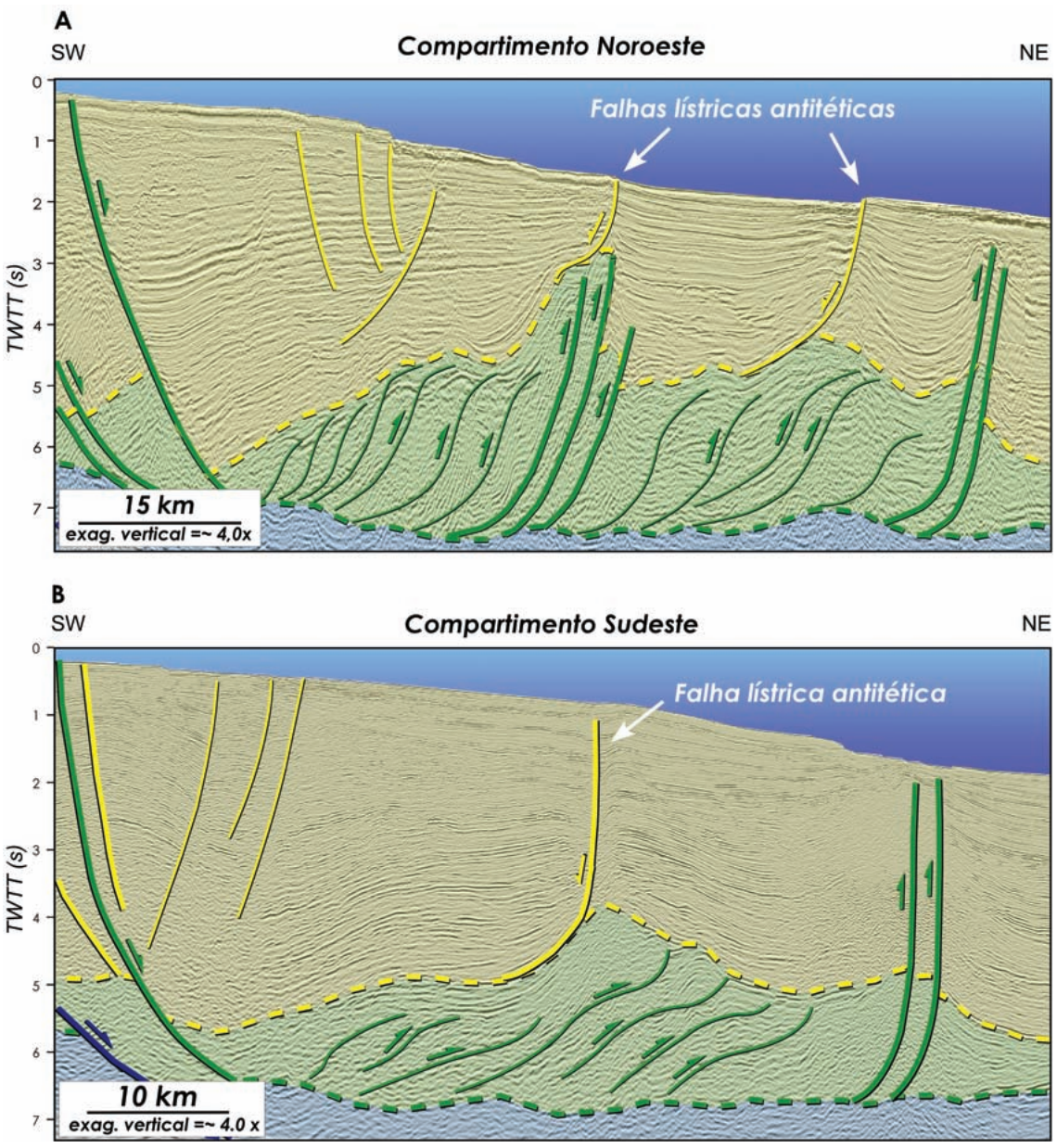

Figura 9 - Detalhes de perfis sísmicos (em tempo) mostrando o horizonte estratigráfico Amarelo, que atua como superfície de descolamento mais superficial da tectônica gravitacional na porção central da Bacia da Foz do Amazonas. (a) falhas normais lístricas antitéticas ancoradas sobre a Superfície de descolamento Amarela na área do Compartimento Estrutura/ Noroeste. (b) falhas normais lístricas antitéticas ancoradas sobre a Superfície de descolamento Amarela na área do Compartimento Estrutural Sudeste.

espessamento sintectônico das cunhas sedimentares delimitadas entre os planos de falha e os rollovers. Já o domínio compressivo localiza-se nas bordas dos depocentros. Uma série de imbricamentos de falhas de empurrão está localizada no limite externo do depocentro D1 no Compartimento NW, enquanto um par de falhas de empurrão delimita distalmente o depocentro D2 na região do Compartimento SE (Fig. 11).

Vale ressaltar que as espessuras apresentadas no mapa de isópacas da Figura 11 não individualizam os depocentros do Leque do Amazonas. Na verdade, estes mapas refletem espessuras decorrentes ao mesmo tempo de processos deposicionais da bacia, por exemplo o desenvolvimento dos depocentros D1 e D2, como também 0 espessamento sedimentar de ordem estrutural, decorrente da deformação dos cinturões de dobramentos (bor- das dos depocentros) que deslizam sobre a Superfície de descolamento Verde.

0 mapa de isópacas das seqüências marinhas da bacia entre a superfície Amarela e o fundo submarino evidencia mais claramente a configuração dos principais depocentros e a compartimentação estrutural do Leque do Amazonas. Os dois principais depocentros D1 e D2, localizados entre os domínios extensivo e compressivo, apresentam-se mais estreitos, ao mesmo tempo em que migram em direção à margem (Fig. 12), relativamente ao observado no mapa anterior (Fig. 11). FaIhas lístricas antitéticas ocorrem na porção central desses depocentros segmentando-os em numerosas mini-bacias confinadas (não representadas na Fig. 12). 0 ancoramento dessas falhas antitéticas ocorre sobre desníveis morfológicos acentuados da 

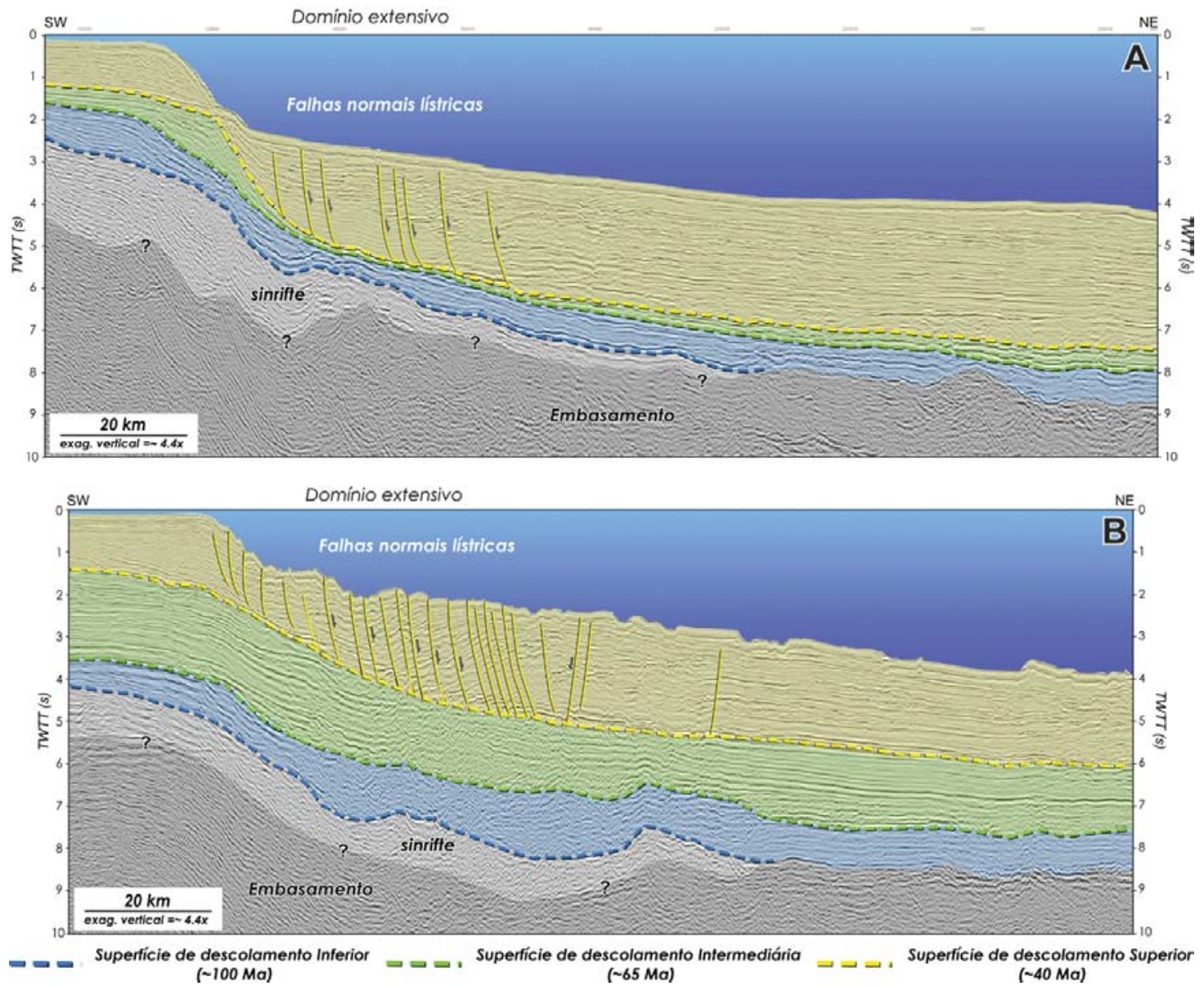

Figura 10 - Seções sísmicas (em tempo) sobre o talude continental Noroeste (a) e Sudeste (b) da Bacia da Foz do Amazonas, adjacentes ao Leque Submarino do Amazonas. As linhas pontilhadas representam: a Superfície de descolamento Azul (horizontes Albiano de 100 Ma segundo Silva et al., 1999), a Superfície de descolamento Verde (horizontes de $\sim 65$ Ma, localizado no limite Cretáceo-Terciário segundo Silva et al., 1999) e a Superfície de descolamento Amarelo (horizontes Eoceno Médio de $\sim 40$ Ma, inferido através de correlação com dados sísmicos publicados de Silva et al., 1999.

Superfície de descolamento Amarela, em regiões onde esta se apresenta intensamente deformada pelos cinturões de dobramentos inativos (Fig. 9). Estas estruturas resultam num impacto morfológico do fundo submarino, ao mesmo tempo em que exercem um controle estrutural na segmentação dos depocentros (Fig. 9). Ao longo do domínio compressivo, o desenvolvimento de mini-bacias confinadas ocorre entre os planos de falhas de empurrão em reposta ao encurtamento progressivo da seção estratigráfica (Figs. 6a e 12).

\section{Modelagem física experimental}

Uma etapa de modelagem física experimental foi conduzida no âmbito desse trabalho no Laboratoire Géosystèmes da Universidade de Lille I, França. No presente estágio das pesquisas, os modelos analógicos não foram projetados com 0 objetivo de se reproduzir todas as variáveis do ambiente geológico da Bacia da Foz do Amazonas/Leque do Amazonas. Os modelos executados visaram a simulação de alguns dos parâmetros físicos envolvidos na tectônica gravitacional da área de estudos, como por exemplo, a presença de múltiplos níveis de descolamento, aplicáveis à compreensão do desenvolvimento de feições específicas mapeadas na área como os cinturões de dobramentos fósseis apresentados nos itens anteriores (Fig. 13a).

Dois modelos (modelos $1 \mathrm{e} 2$ ) foram realizados simulando a ocorrência de deslizamento de seções sedimentares na presença de 2 níveis móveis superpressurizados, e sua influência no grau de deformação da seção, com variação na espessura das camadas rúpteis (camadas sedimentares).

0 modelo 1 simula a presença de dois níveis móveis de 0,5 cm de espessura e dois níveis frágeis de $1,0 \mathrm{~cm}$ cada, perfazendo um total de $3 \mathrm{~cm}$ de camadas pré-tectônicas. 0 resul- 


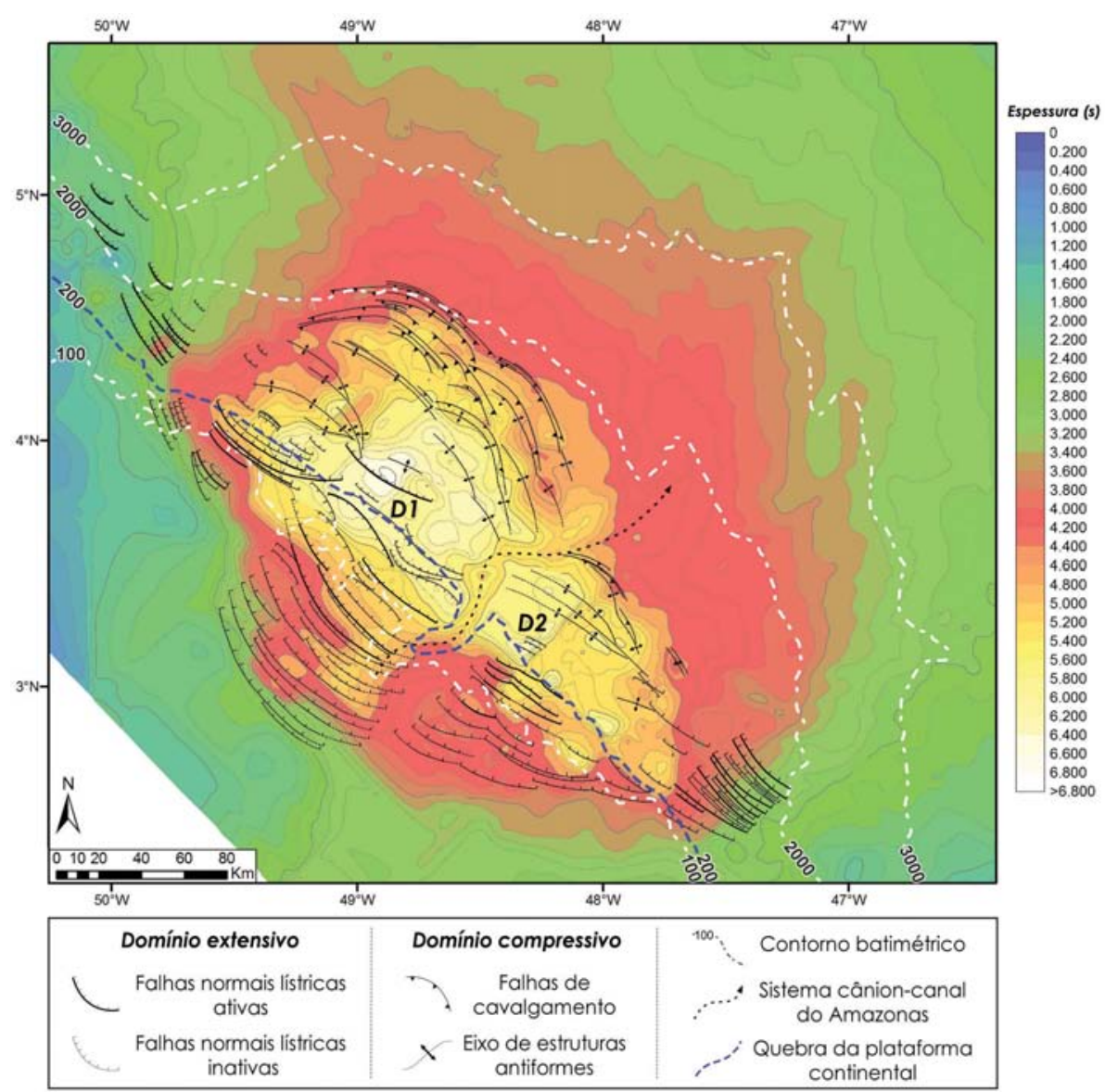

Figura 11 - Mapa conjugado de estruturas e de isópacas (espessura em tempo) entre a superfície de décollement intermediária (Verde) e o fundo submarino (ver Figs. 7 e 8). D1 e D2 são os principais depocentros da margem para o intervalo temporal considerado ( $100 \mathrm{Ma}$, segundo correlação com dados de Silva et al., 1999).

tado da deformação demonstra uma zona compressiva formada por falhas de cavalgamento isoladas, ou agrupadas em frentes compressivas (fold-and-thrust belts) (Fig. 13b). A deformação se inicia por dobramentos que terminam por dar origem a imbricamentos de falhas reversas (thrust sheets), que posteriormente evoluem para falhas de cavalgamento constituídas por feições de rampa-platô (ramp-and-flat thrust fault) e feições de retro-empurrão (backthrust). De forma geral, os planos de faIha verticalizam-se, e em seguida passam a se movimentar horizontalmente, até que aumenta a resistência ao movimento horizontal e as camadas são impossibilitadas de deslizar, se dobram e formam anticlinais (fault-bend folds e fault propagation faults). 0 efeito final do encurtamento é 0 espessamento da seção ao longo da frente compressiva (Fig. 13b).

0 modelo 2 é constituído por camadas frágeis menos espessas que as do modelo $1(0,5 \mathrm{~cm})$. Via de regra, foi observado 0 desenvolvimento de estruturas semelhantes. A diferença reside no maior grau de cavalgamento, o que resulta na ocorrência pre- dominante de falhas de cavalgamento do tipo rampa-platô ( rampand-flat thrust fault) e no desenvolvimento de estruturas em duplex (Fig. 13c). A simulação de níveis frágeis menos espessos no modelo $2(0,5 \mathrm{~cm})$ resultou num maior grau de encurtamento da seção e na tendência da zona compressiva se constituir num cinturão compressivo único mais amplo (fold-and-thrust belt). Da mesma forma, 0 empilhamento e 0 espessamento da seção são mais significativos que no modelo 1 (Figs. 13a e 13b).

Durante a execução dos modelos, observamos setores ou períodos de tempo onde 0 stress horizontal ao longo das duas superfícies age desacopladamente, e os níveis de décollement ou descolamento atuam separadamente; ou setores dos modelos ou períodos de tempo em que o nível de décollement ou descolamento superficial é deformado em compressão, deslizando sobre a superfície basal (Fig. 13).

Os modelos realizados auxiliaram também na compreensão de alguns aspectos do funcionamento mecânico do sistema gravitacional. Por exemplo, apesar das diferenças estruturais e dos 


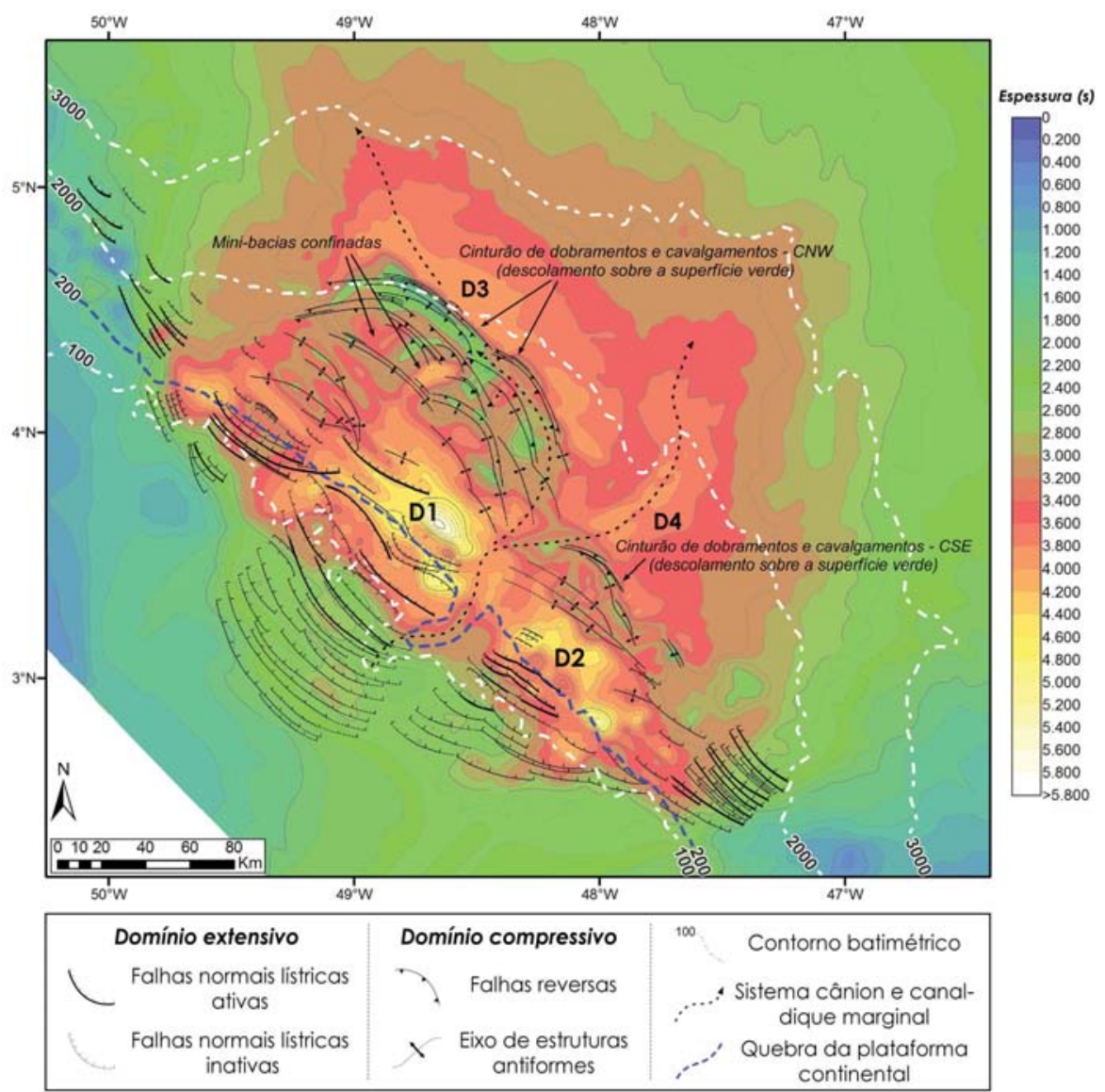

Figura 12 - Mapa conjugado de estruturas e de isópacas (espessura em tempo) entre a superfície de décollement superficial (Amarela) e o fundo submarino (ver Figs. 7 e 8). D1 e D2 são os principais depocentros da margem para 0 intervalo temporal considerado ( $40 \mathrm{Ma}$, segundo correlação com dados sísmicos de Silva et al., 1999).

diferentes graus de encurtamento observados ao final de cada modelo, um importante parâmetro mecânico que se repete nos modelos 1 e 2 diz respeito à distribuição espacial e à cronologia das estruturas compressivas. Em ambos os casos, a deformação se inicia uma vez atingida a superpressurização calculada para se ultrapassar o coeficiente de resistência associado à espessura da seção de cada modelo. Mas no início da deformação, a primeira falha reversa se forma sempre numa posição distal dos sistemas; e à medida que 0 colapso gravitacional avança, as falhas reversas migram em direção montante do modelo (análoga à direção do continente no caso real).

\section{DISCUSSÃO}

A análise estrutural realizada neste trabalho mostra que a complexidade estrutural e as dimensões dos compartimentos estruturais NW e SE da tectônica gravitacional da Bacia da Foz do Amazonas evoluem no espaço e no tempo atrelados às variações espaciais do desenvolvimento dos principais depocentros ao longo da margem. Pode-se observar, por exemplo, como descrito no capítulo anterior, que o cinturão de dobramentos fóssil presente no Compartimento SE, e o cinturão de dobramentos modernos que caracteriza o Compartimento NW, descolam-se sobre a superfície Verde (superfície de descolamento intermediária) (Figs. 9 e 14), e distribuem-se sistematicamente ao longo das bordas dos depocentros D1 e D2 (Fig. 11). A complexidade estrutural que caracteriza estes cinturões gravitacionais compressivos parece responder às variações laterais de desenvolvimento dos depocentros durante a deposição das seqüências do Leque do Amazonas. Os cinturões são mais complexo a noroeste, na região de desenvolvimento do depocentro D1 (Fig. 14), indicando eventos deformacionais de longa duração, representados por múltiplas frentes compressivas sucessivas e pelo maior impacto da deformação na morfologia do fundo oceânico (Fig. 7).

Modelos conceituais simplificados apresentados a seguir propõem compreender a variação da complexidade estrutural dos 

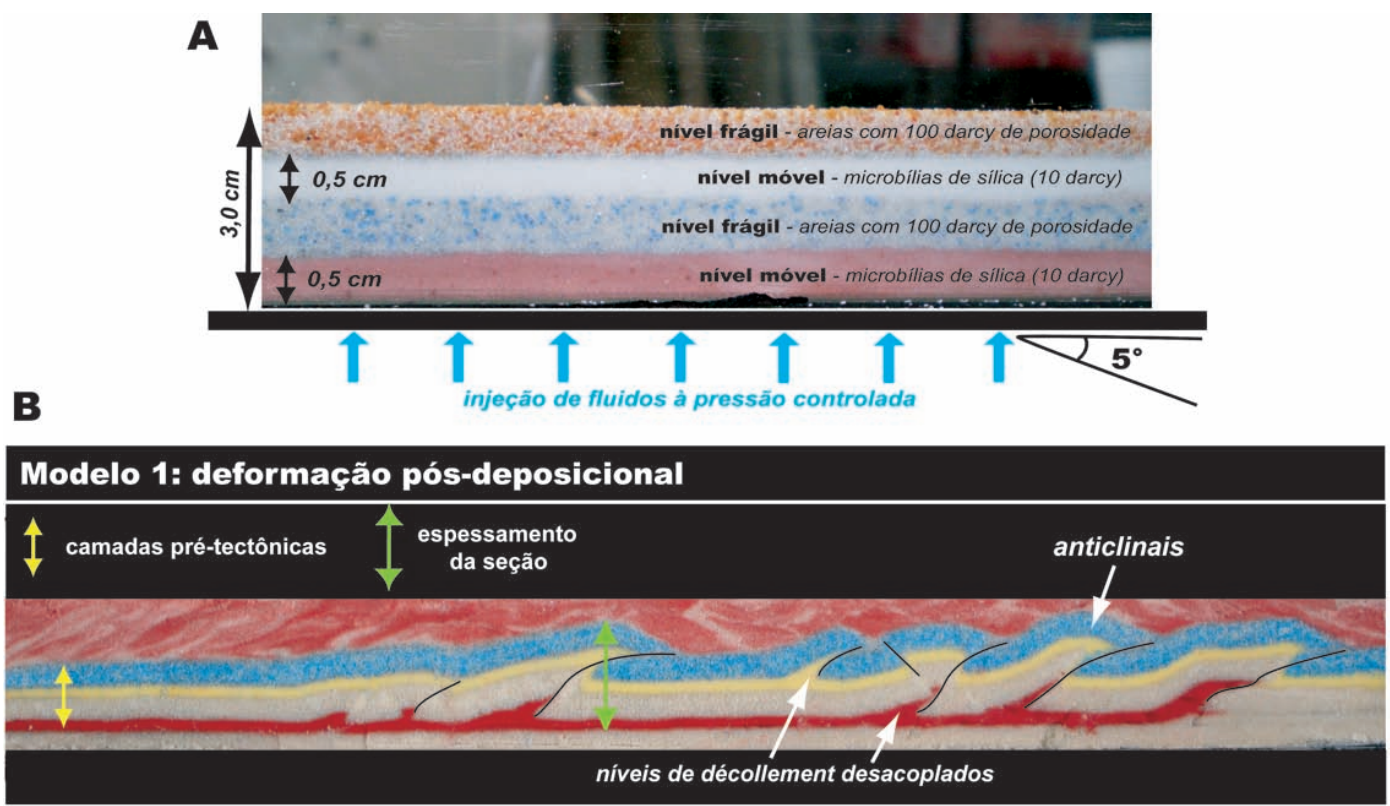

C

\section{Modelo 2: deformação pós- e sin-deposicional}

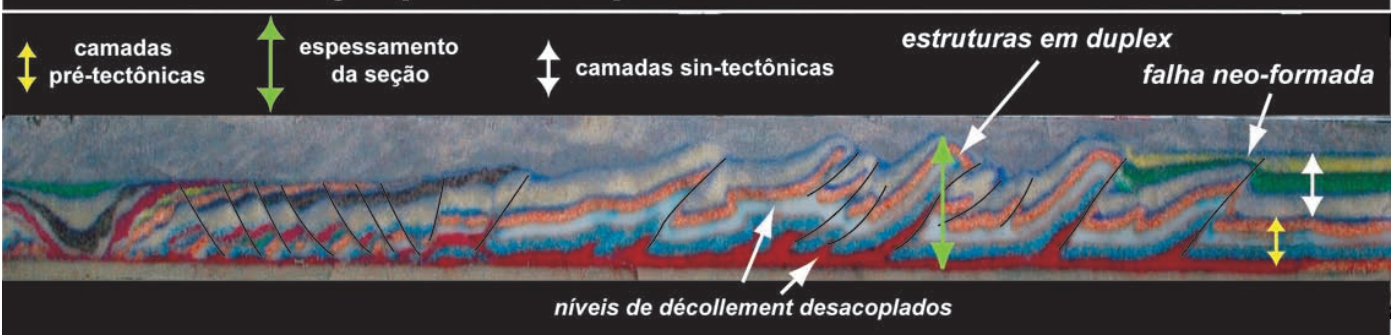

Figura 13 - (a) Esquema simplificado do dispositivo de modelagem experimental desenvolvido pelo Professor Bruno Vendeville, no Laboratório de Modelagem Analógica da Universidade de Lille 1-França, utilizado nas experiências. 0 dispositivo opera com injeção de fluidos à pressão controlada (injetado na parte inferior do dispositivo) capaz de simular a ocorrência de níveis móveis durante a realização dos modelos experimentais. (b) e (c) Vista lateral dos modelos físicos experimentais 1 e 2, mostrando diferentes graus de deformação envolvida no desenvolvimento de cinturões gravitacionais de dobramento e cavalgamento (ver texto para maiores detalhes).

cinturões de dobramentos e cavalgamentos, relacionando-os às variações no grau de deformação (encurtamento), à sobrecarga sedimentar (majoritariamente às seqüências do Leque submarino do Amazonas) e à atuação diferencial do nível estratigráfico mais superficial (superfície Amarela) como superfície de descolamento.

\section{Deformação ativa mais incipiente do Compartimento SE}

0 cinturão gravitacional do Compartimento SE é formado por um imbricamento de unidades estruturais compressivas (imbricate thrust sheets), que formam um cinturão de dobramentos na sua maior parte inativo (soterrado) (Fig. 8). Sua configuração estrutural sugere um primeiro estágio principal de deformação envolvendo o colapso gravitacional de um pacote pré-tectônico multia- camadado, de espessura razoavelmente constante (pré-deposiç̧ão do Leque do Amazonas), formado pela superposição de múltiplos níveis de décollement (Fig. 15a). Este estágio de deformação pode ser exemplificado pelos modelos físicos experimentais 1 e 2 (Fig. 13), que simulam o colapso gravitacional de camadas pré-tectônicas e resultam em cinturões de dobramentos de configuração semelhante aos cinturões soterrados observados no Compartimento SE. Um análogo pode ser exemplificado pela feição de colapso gravitacional presente na Bacia de Orange (Fig. 16a), margem da Namíbia (Butler \& McCaffrey, 2008).

Os dobramentos observados nas camadas sobrejacentes ao cinturão fóssil podem ser explicados por uma compressão adicional, acompanhada da reativação das falhas reversas, durante a deposição subseqüente de camadas sintectônicas pré- 


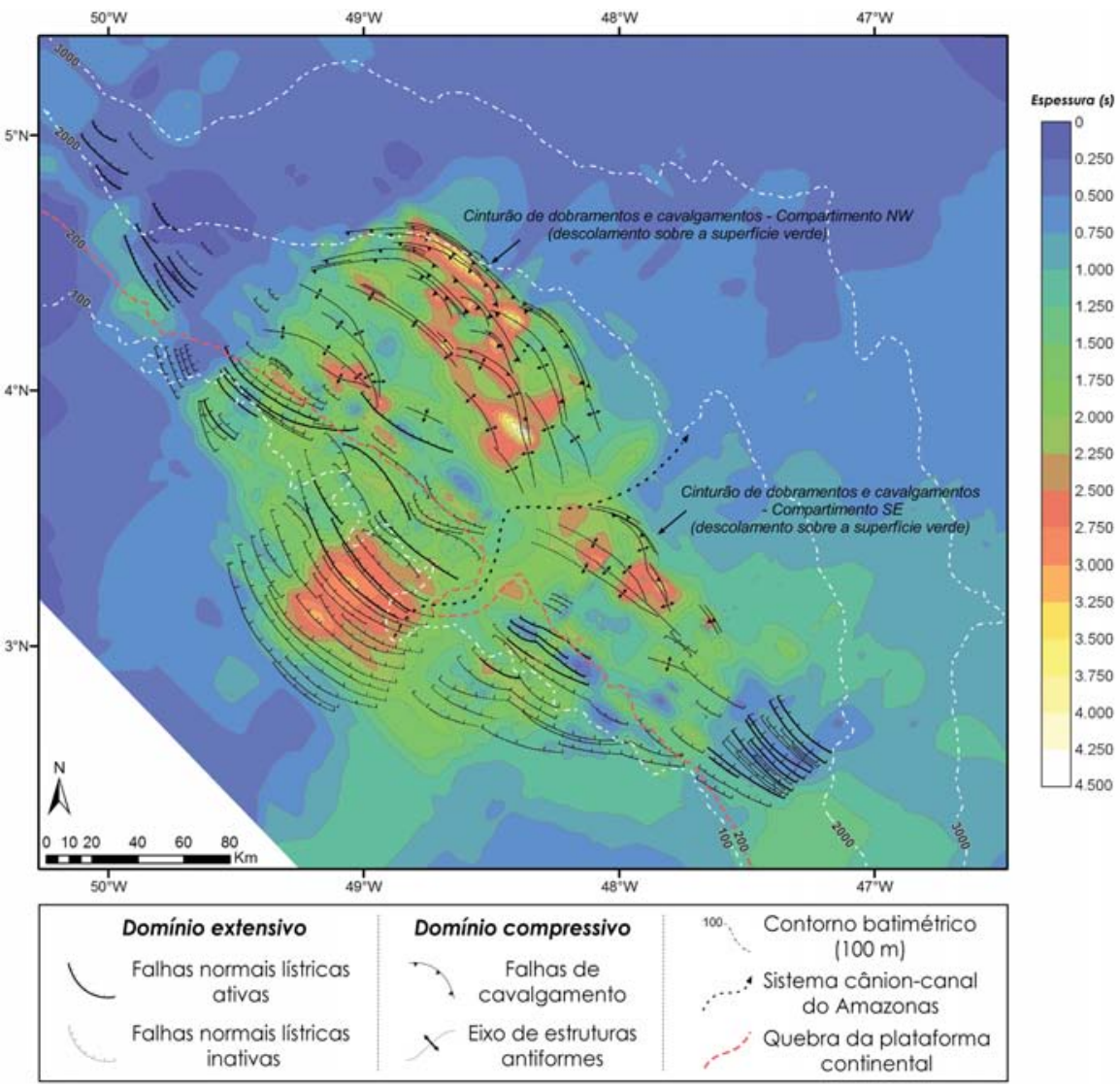

Figura 14 - Mapa conjugado de estruturas e de isópacas (espessura em tempo) entre a superfície de décollement intermediária (Verde) e superficial (Amarela) (ver Figs. 7 e 8).

deposição do Leque do Amazonas. Tal deposição teria levado à reativação de falhas de empurrão, resultando no espessamento estrutural do cinturão e na formação dos próprios dobramentos (drape folding) das camadas sobrejacentes sintectônicas (Fig. 15b). Neste estágio, o nível estratigráfico Amarelo teria atuado como superfície de descolamento, impedindo a transferência e a propagação da compressão do cinturão abaixo para as camadas sobrejacentes (Fig. 15b). Deste modo, o stress cisalhante permaneceria confinado entre as superfícies de descolamento intermediária (Verde) e superior (Amarela) da bacia. Um análogo poderia ser exemplificado pelo cinturão de dobramentos gravitacionais de águas profundas da Bacia do Pará-Maranhão (Fig. 16b, Zalán, 2005), que apresenta dobramentos (drape folds) semelhantes aos observados no Compartimento SE.

\section{Deformação ativa mais desenvolvida do Compartimento NW}

0 cinturão gravitacional do Compartimento NW é formado por uma sucessão de falhas reversas que se descolam sobre a su- perfície Verde, e afetam toda a seqüência marinha sobreposta da bacia, resultando num amplo cinturão de dobramento gravitacional moderno (ativo) (Figs. 7 e 9a). Sua configuração estrutural atual sugere estágios de colapso gravitacional de um pacote pré-tectônico, seguindo a mesma evolução descrita acima para 0 compartimento SE (Figs. 15a e 15b). Neste compartimento, no entanto, 0 desenvolvimento preferencial dos principais depocentros sedimentares do Leque do Amazonas resultou num prisma sedimentar sintectônico mais espesso que no Compartimento SE, cuja sobrecarga sedimentar foi capaz de produzir um maior encurtamento do cinturão basal. 0 fenômeno de sobrecarga sedimentar levou à conseqüente reativação de grande número de falhas reversas do cinturão pré-leque, que se propagam verticalmente para cima, constituindo o mais amplo e espesso cinturão de dobramentos ativos da tectônica gravitacional da Bacia da Foz do Amazonas (Fig. 15c). Um processo de deformação sindeposicional similar parece ter ocorrido no Compartimento SE. Entretanto, a cobertura sedimentar menos espessa resultante do empiIhamento das seqüências do leque (depocentro D2) teria resultado somente na reativação sinsedimentar de parte do cinturão, repre- 


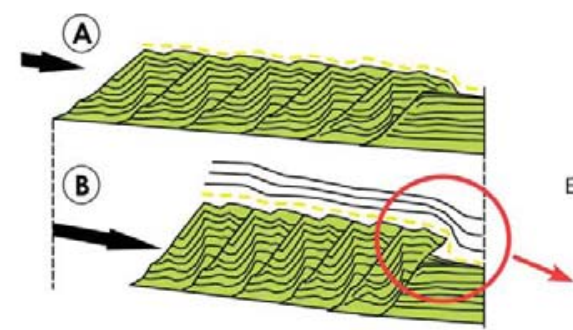

Colapso gravitacional e compressāo das unidades pré-tectőnicas

Encurtamento sindeposicional da seção (préleque) resultando na reativação da compressão e no espessamento estrutural

Dobramento das camadas sintectônicas (drape folding)
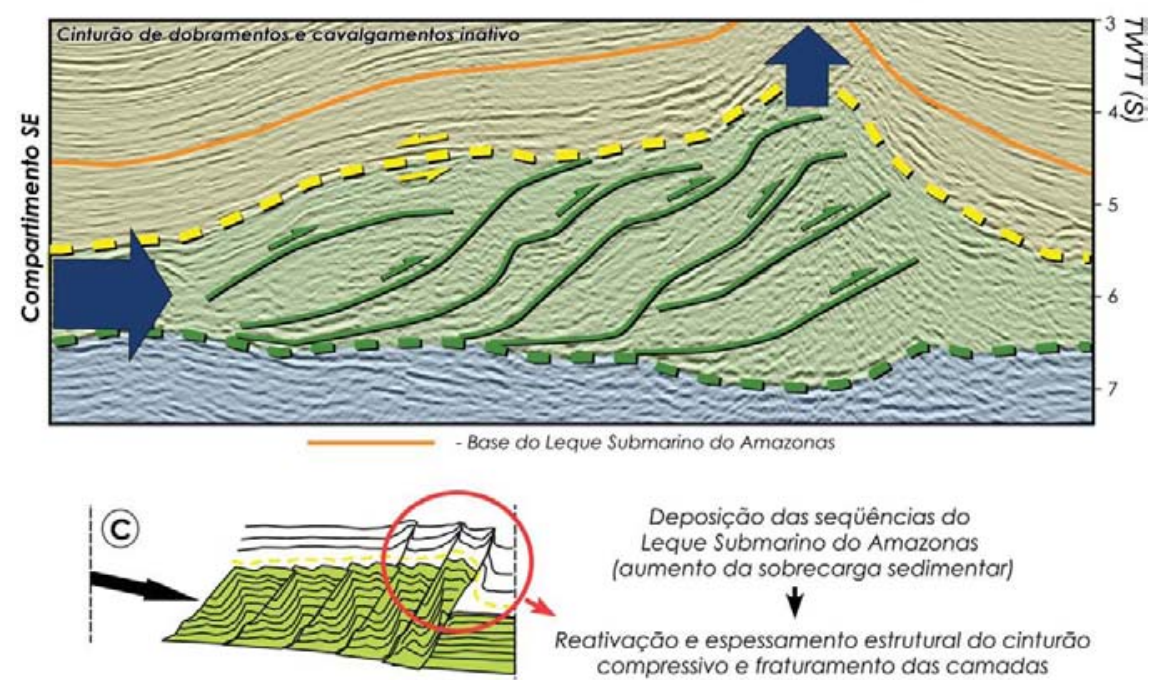

Deposição das seqüências do

Leque Submarino do Amazonas (aumento da sobrecarga sedimentar)

Reativação e espessamento estrufural do cinturão compressivo e fraturamento das camadas sintectônicas sobrepostas (thrust faulting)

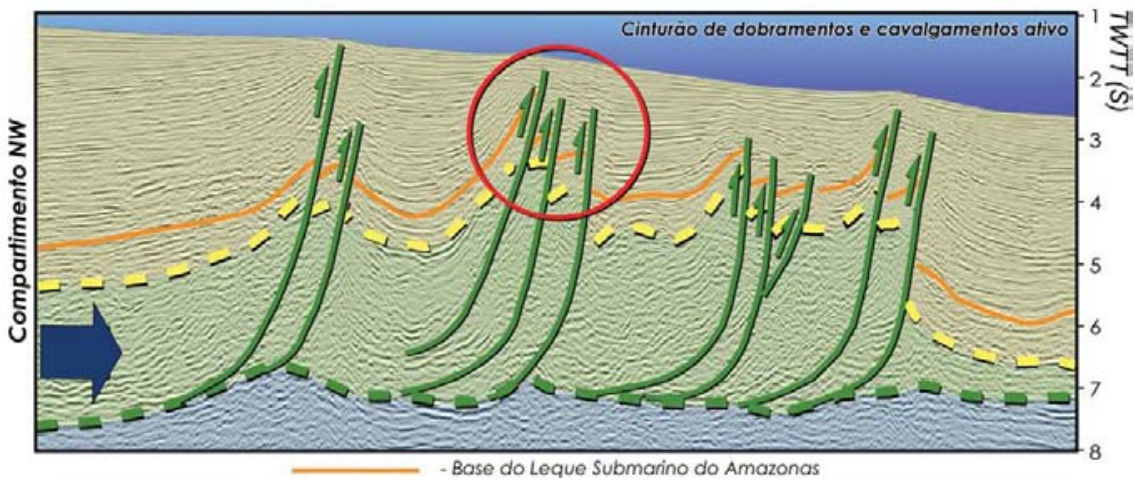

Figura 15 - Modelos conceituais simplificados da evolução dos cinturões de dobramentos e cavalgamentos gravitacionais dos Compartimentos SE e NW da Bacia da Foz do Amazonas, relacionando diferentes graus de deformação (encurtamento) à evolução sedimentar da bacia, principalmente a instalação da espessa cunha sedimentar siliciclástica do sistema turbidítico do Leque do Amazonas ( $10 \mathrm{~km}$ de espessura, segundo Silva et al., 1999).

sentado por um par de falhas reversas isoladas que se propaga localmente para o topo da seqüência, compondo 0 atual cinturão ativo do Compartimento SE (Fig. 8).

A análise sísmica efetuada neste trabalho evidencia que o deslizamento da seção marinha da Bacia da Foz do Amazonas ocorreu ao longo de distintas superfícies de descolamento e, aparentemente, em diferentes estágios de evolução da margem. Pelo menos três níveis estratigráficos principais funcionaram em al- gum momento como níveis de descolamento, em escala regional ou local: a superfície basal Azul (de idade Albiano, 100 Ma, segundo Silva et al., 1999), a superfície intermediária Verde ( 65 , limite Cretáceo-Terciário, Silva et al., 1999) e a superfície superior Amarela ( 40, Eoceno Médio, segundo correlação com dados sísmicos publicados de Silva et al., 1999) (Fig. 17). A análise sísmica mostra também que a complexidade estrutural e 0 nível de atividade dos cinturões compressivos seguem as 

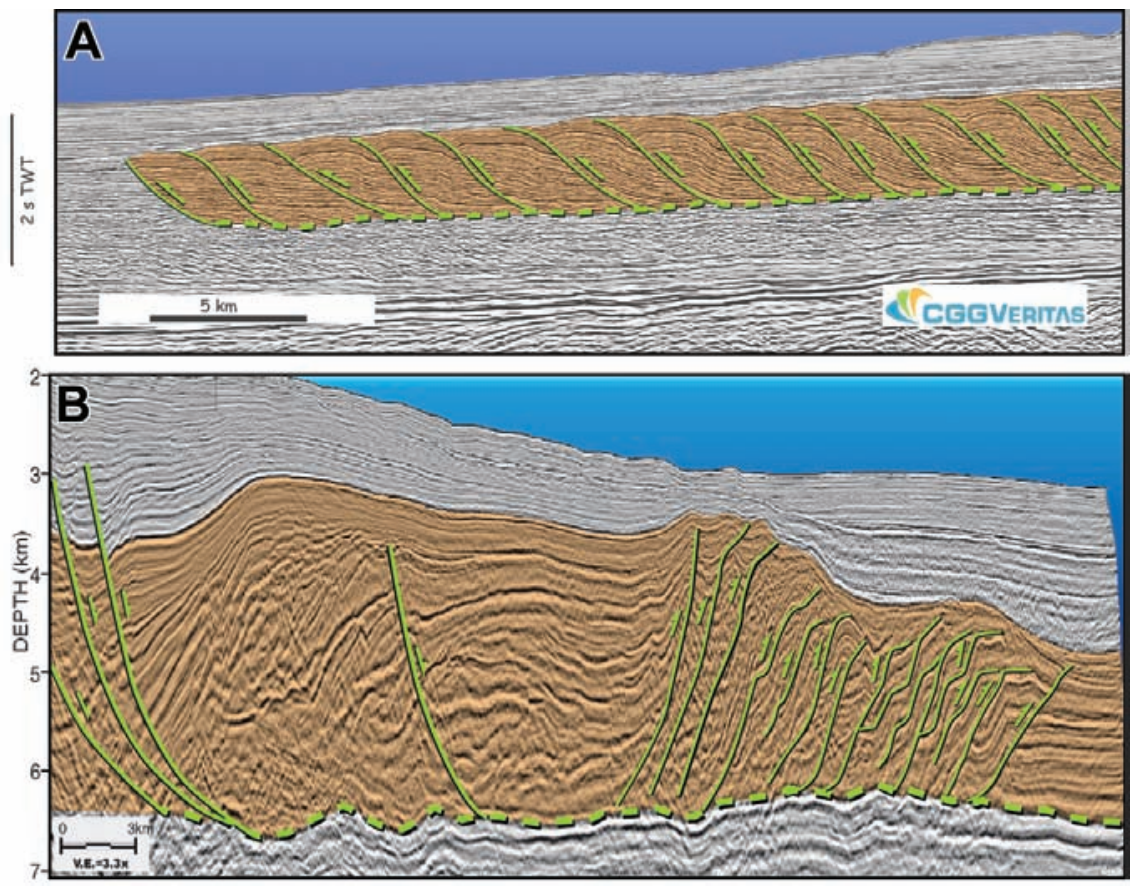

Figura 16 - Exemplos sísmicos (em tempo) de análogos de cinturões gravitacionais de dobramentos e cavalgamentos na Bacia do Pará-Maranhão, margem equatorial brasileira (modificado de Zalán, 2005) e na Bacia de Orange, margem continental da Namíbia (modificado de Butler \& McCaffrey, 2008).

variações laterais dos principais depocentros da bacia, que se desenvolvem preferencialmente em direção a noroeste (Fig. 18). Por outro lado, Cobbold et al. (2004) atribuíram o desenvolvimento estrutural assimétrico na bacia às variações espaciais nos níveis de pressurização dos fluidos intersticiais promovidos pela entrada de gás termogênico proveniente de rochas fonte do Cenomaniano-Turoniano, Iocalizadas em sua maioria abaixo do Compartimento NW. Os autores argumentam que 0 grande espessamento das seqüências marinhas que se desenvolvem sobre as superfícies de descolamento aqui chamada de Verde (atualmente da ordem de $10 \mathrm{~km}$ ), resultaria em grande compactação e na impossibilidade da existência de níveis compostos por argilas móveis. Neste contexto, os autores, baseados em dados geoquímicos, atribuem a superpressurização à contribuição de fluidos externos à compactação, neste caso hidrocarbonetos provenientes de rochas fontes subjacentes (gás metano). Entretanto, os modelos apresentados acima fornecem um possível panorama de evolução da tectônica gravitacional na bacia que se dá por etapas, acompanhando o espessamento progressivo da coluna sedimentar, até a implantação do espesso prisma sedimentar representado pelo sistema turbidítico do Amazonas. Neste caso, a evolução estrutural da bacia não exclui a existência de níveis de décollement (nível basal móvel) nos estágios iniciais de desenvolvimento da tectônica gravitacional da bacia, como simulados, por exemplo, nos modelos analógicos que envolvem empilhamentos sedimentares de espessura comparável à dos cinturões fósseis do Compartimento SE. A existência de níveis móveis superpressurizados por compactação somente seria impossibilitada com o espessamento das seqüências sedimentares da bacia durante a construção do leque submarino (cerca de $10 \mathrm{~km}$ ). Assim, ambas as explicações (sobrecarga sedimentar diferencial e geração de hidrocarbonetos) não nos parecem excludentes e podem ocorrer concomitantemente, promovendo a formação das descontinuidades mecânicas (superfícies de descolamento) ao Iongo de horizontes estratigráficos, motor da tectônica gravitacional na Bacia da Foz do Amazonas.

Além disso, as variações no grau de encurtamento da cobertura sedimentar entre os compartimentos estruturais da Bacia da Foz do Amazonas, representadas pelo maior encurtamento da cobertura sedimentar no Compartimento NW, remetem a questionamentos sobre como se desenvolve a interação entre eles. No presente trabalho, não foram implementados métodos de restauração de seção para quantificar o deslocamento horizontal das seqüências deformadas em cada compartimento estrutu- 


\section{A Horizonte estratigráfico azul}

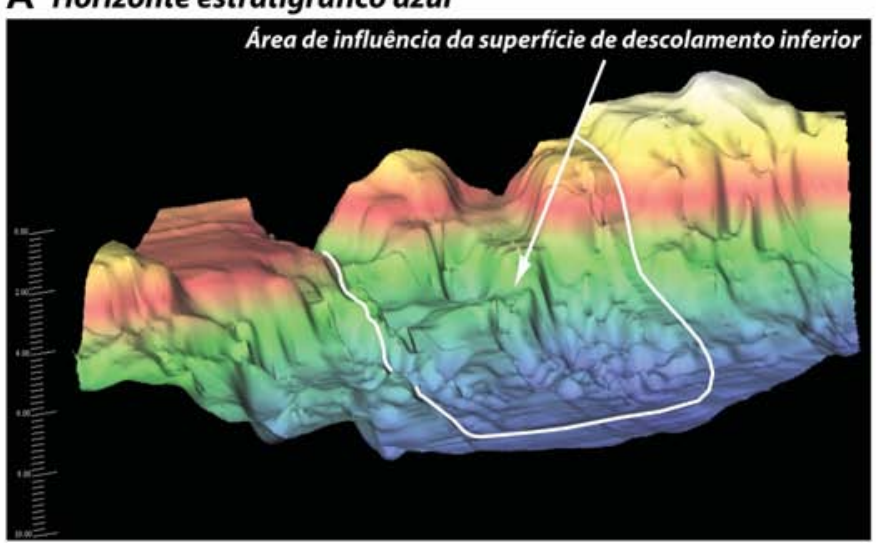

B Horizonte estratigráfico verde

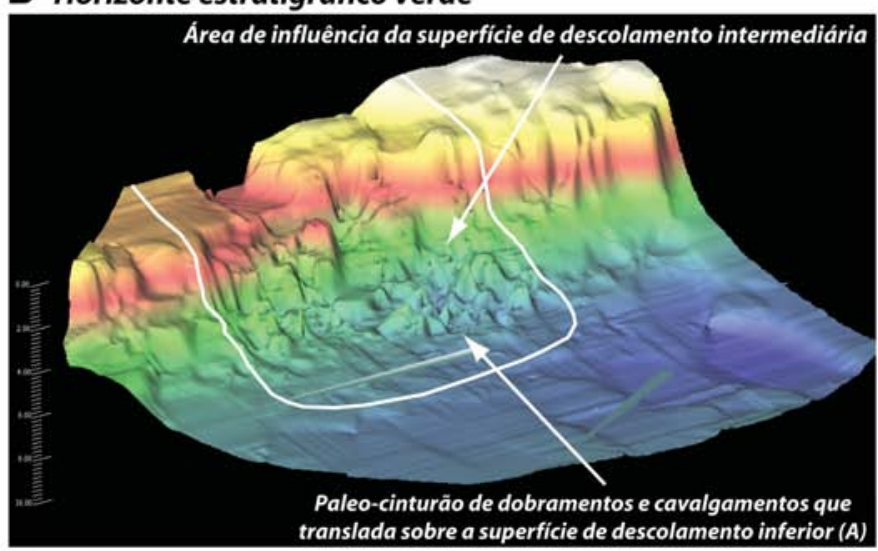

\section{Horizonte estratigráfico amarelo}

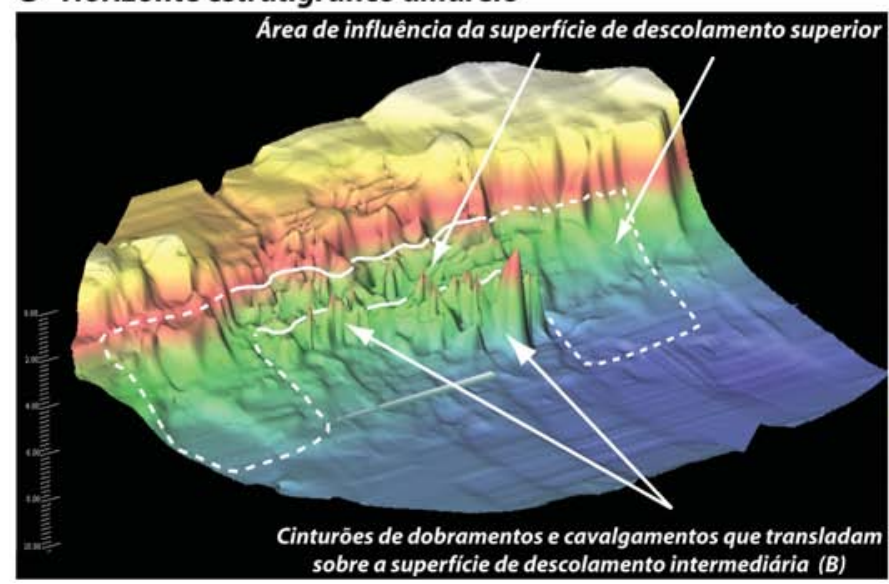

Figura 17 - Morfologia 3D dos principais níveis estratigráficos que podem atuar como níveis de descolamento na Bacia da Foz do Amazonas, cujas áreas potenciais de deslizamento (regionais ou locais) estão delimitadas aproximadamente pelas linhas brancas. As linhas tracejadas delimitam zonas lateralmente correlacionáveis ao nível estratigráfico Amarelo (superior), representando área de nível potencial de descolamento.

ral. Mas, a análise estrutural e os dados batimétricos indicam que os compartimentos estruturais se interagem através de uma rampa de revezamento (relay-ramp). Esta rampa, além de sugerir um relativo movimento de transferência entre os compartimentos, acomodando as diferentes taxas de encurtamento, condiciona estruturalmente o sistema cânion-canal submarino do Amazonas e segmenta os dois principais depocentros da Bacia da Foz do Amazonas e do leque submarino (Fig. 19). 


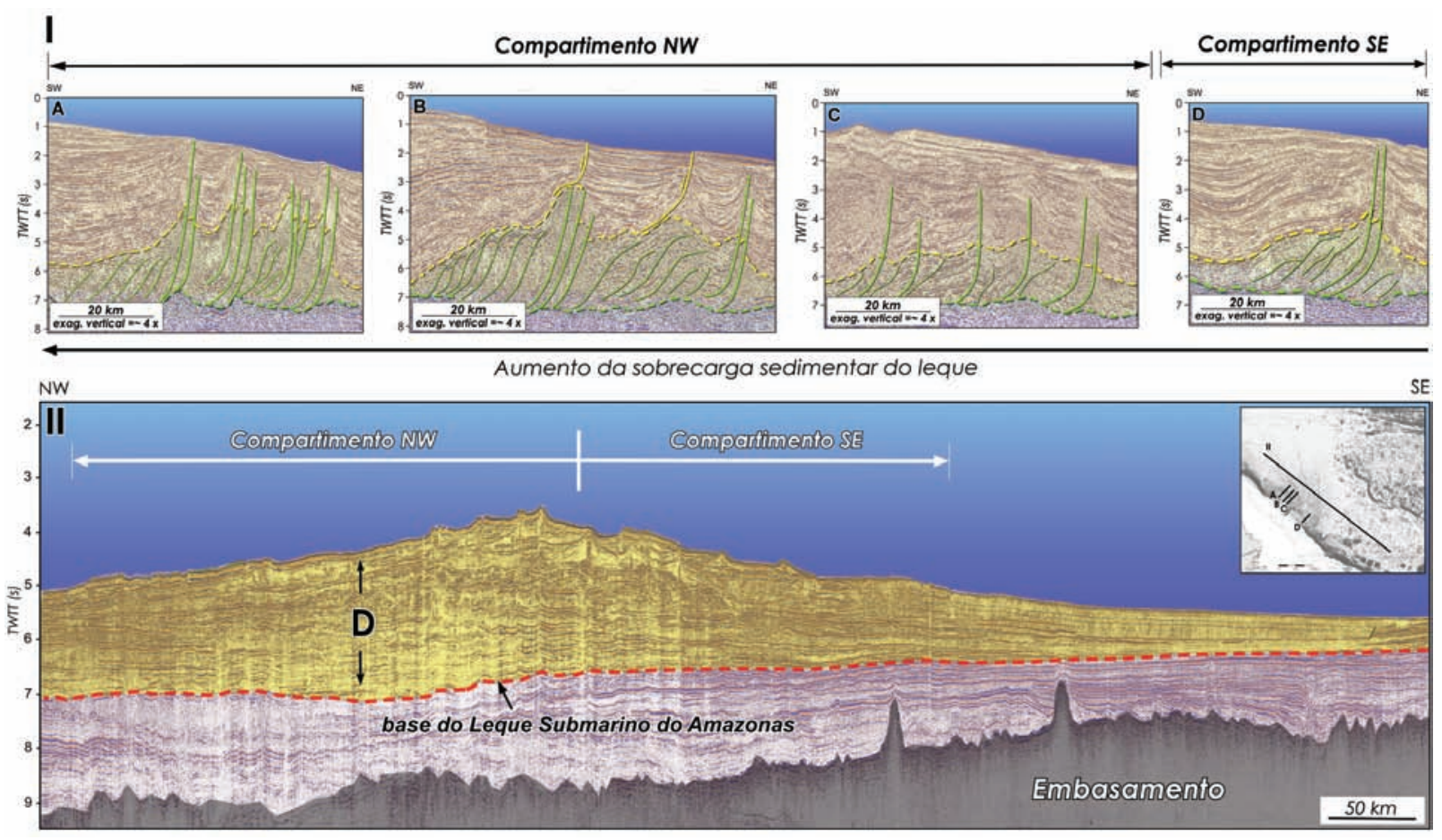

Figura 18 - I. Série de perfis sísmicos (em tempo) mostrando a variação dos estilos estruturais dos cinturões de dobramentos e cavalgamentos, seguindo o desenvolvimento dos principais depocentros da margem, localizados preferencialmente na porção NW da Bacia da Foz do Amazonas - Compartimento Noroeste (detalhes A, B e C) da tectônica gravitacional. II. Perfil sísmico ao longo da província morfológica do Leque Médio do Amazonas, mostrando o desenvolvimento do principal depocentro das seqüências marinhas (em D) na porção NW da Bacia da Foz do Amazonas.

Finalmente, a configuração e distribuição dos principais depocentros individualizados evidenciam o papel da tectônica gravitacional sobre a evolução sedimentar da Bacia da Foz do Amazonas e do Leque do Amazonas, em particular. A compartimentação estrutural parece controlar o desenvolvimento dos principais depocentros da bacia que se desenvolvem proximalmente à margem nos Compartimentos NW e SE (depocentros D1 e D2). Da mesma forma, a estruturação parece controlar as direções de dispersão sedimentar do leque, pois o espalhamento lateral dos sistemas canal-dique marginal ocorre na bacia profunda, apenas ao final do confinamento estrutural do sistema cânion-canal do Amazonas, via rampa de revezamento (relay-ramp) entre os dois compartimentos (Figs. 12 e 19).

\section{CONCLUSÕES}

A análise estrutural realizada no presente trabalho nos traz uma série de novas informações que auxiliam na compreensão dos mecanismos da tectônica gravitacional e de sua evolução na Bacia da Foz do Amazonas:

(1) 0 desenvolvimento do arcabouço estrutural da tectônica gravitacional na bacia é controlado pela atuação con- junta do potencial gravitacional e da sobrecarga sedimentar resultando em um sistema extensivo - compressivo mecanicamente conectado (Figs. 3, 7 e 8). As falhas normais lístricas proximais e os cinturões gravitacionais de dobramentos e cavalgamentos distais (fold-and-thrust belts) formam um amplo nappe gravitacional de cerca de $200 \mathrm{~km}$ de largura, cujos limites acompanham as bordas dos depocentros da bacia, evidenciando a inter-relação entre a evolução sedimentar e estrutural da tectônica gravitacional (Figs. 3 e 11). A geometria e a complexidade dos cinturões compressivos variam lateralmente em função de mudanças espaciais no desenvolvimento dos depocentros do Leque do Amazonas. Os cinturões são significativamente mais complexos no Compartimento NW e refletem a maior influência da sobrecarga sedimentar diferencial, marcada pelo desenvolvimento preferencial dos principais depocentros em direção a noroeste (Fig. 18);

(2) 0 arcabouço estrutural ativo apresenta uma segmentação de primeira ordem marcada por dois compartimentos estruturais individualizáveis - os Compartimentos NW e SE. Os compartimentos estruturais se interagem através 


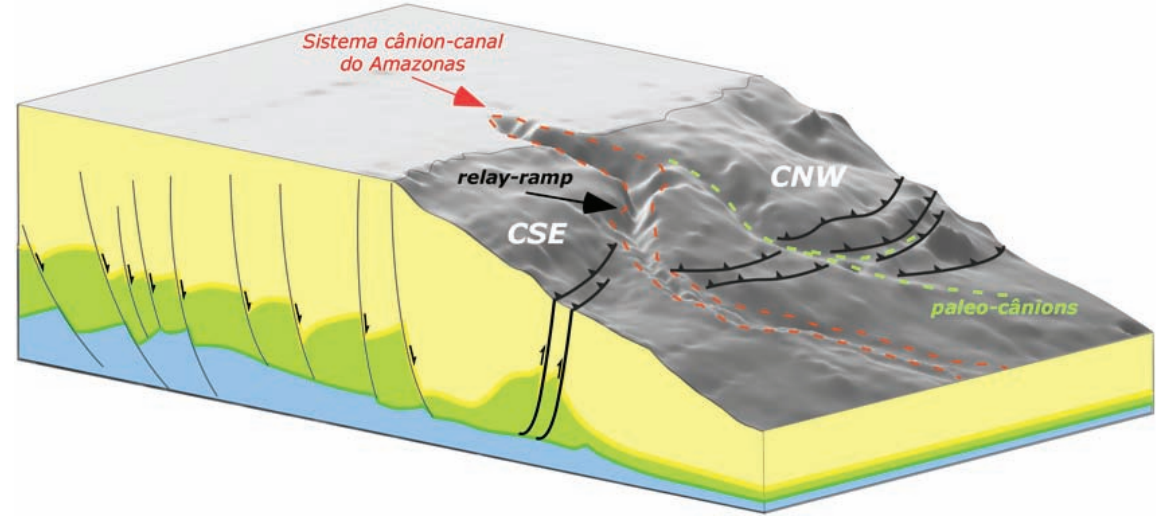

Figura 19 - Bloco diagrama 3D ilustrando a interação estrutural, via rampa de revezamento "relay-ramp", entre os Compartimentos Estruturais NW e SE. A rampa de revezamento é também responsável pelo condicionamento estrutural do sistema cânion-canal do Amazonas. CNW = Compartimento Noroeste e CSE = Compartimento Sudeste.

de uma rampa de revezamento "relay-ramp", que se desenvolve entre suas respectivas zonas compressivas (Fig. 19). Esta rampa, além de sugerir um relativo movimento de transferência entre os compartimentos, condiciona estruturalmente 0 sistema cânion-canal submarino do Amazonas e segmenta os dois principais depocentros da Bacia da Foz do Amazonas e do leque submarino. Além de exercer um controle estrutural sobre o sistema cânion-canal submarino do Amazonas, e conseqüentemente sobre a direção de dispersão sedimentar do leque submarino, a compartimentação estrutural favorece o maior desenvolvimento dos depocentros na porção NW da bacia, através da criação sintectônica de espaço de acomodação sedimentar;

(3) 0 deslizamento gravitacional das seções estratigráficas da bacia ocorreu ao longo de distintas superfícies de descolamento, e aparentemente, em diferentes estágios evolutivos da margem. Pelo menos três níveis estratigráficos principais funcionaram em algum momento como níveis de décollement, em escala regional ou local: a superfície inferior Azul (de idade Albiano, Silva et al., 1999), a superfície intermediária Verde (localizada no limite CretáceoTerciário, Silva et al., 1999) e a superfície superior Amarela (de idade provável Eoceno Médio, segundo correlação com dados sísmicos de Silva et al., 1999) (Fig. 17). Um sistema gravitacional composto por falhas normais proximais - cinturão gravitacional distal se descola sobre a superfície de descolamento inferior. Enquanto suas falhas normais se propagam em direção ao topo da seqüência sedimentar da bacia na região da plataforma continental e talude, seu domínio distal compõe um paleo-cinturão compressivo fóssil, cuja deformação não se propaga para níveis estratigráficos superiores e está mecanicamente desacoplada do sistema através da superfície de descolamento intermediária Verde (Fig. 17a). A maior parte das estruturas relacionadas ao colapso gravitacional na bacia se descola sobre a superfície intermediária Verde (limite Cretáceo-Terciário, Fig. 17b). Os cinturões compressivos modernos associados a esse nível desempenham um papel fundamental no controle estrutural dos principais depocentros, deformando as seqüências marinhas da bacia e do Leque do Amazonas, e afetando significativamente a morfologia do fundo submarino. Finalmente, a superfície Amarela, mais superior, atua localmente como nível de descolamento nas imediações dos cinturões compressivos onde ancoram falhas normais antitéticas, que segmentam e estruturam os principais depocentros do Leque do Amazonas (Figs. 9 e 17c). Em direção às porções noroeste e sudeste da bacia, a superfície Amarela grada lateralmente para superfícies de décollement basal sobre a qual se desenvolvem preferencialmente feições e depósitos de colapso gravitacional (movimentos de massa) que afetam 0 extremo noroeste e 0 extremo sudeste da Bacia da Foz do Amazonas (Figs. 10 e 17c) (Araújo et al., 2009; Silva et al., 2009).

\section{AGRADECIMENTOS}

Os autores agradecem ao CNPq/CTPETRO e ao programa francobrasileiro CAPES-COFECUB pelo apoio financeiro e pelas bolsas de doutoramento para o projeto. Agradecemos igualmente às 
empresas GAIA e FUGRO, como também ao Programa LEPLAC e à Agência Nacional do Petróleo, Gás Natural e Biocombustíveis (ANP) pela cessão das linhas sísmicas utilizadas neste estudo. Agradecemos à empresa SMT pelo uso de licenças educacionais do programa Kingdom Suite ${ }^{\circledR}$. Gostaríamos ainda de agradecer à ANP (programa PRH 11-UFF) pelas bolsas de mestrado concedidas ao primeiro e sexto autores, e à CAPES pela bolsa de mestrado do último autor. Finalmente, agradecemos ao CNPq pelas bolsas de pesquisa concedidas ao segundo e terceiro autores.

\section{REFERÊNCIAS}

ARAÚJO EF. 2008. Processos de instabilidade gravitacional multiescala na Bacia da Foz do Amazonas: depósitos de transporte de massa e megadeslizamentos. Dissertação de Mestrado. Departamento de Geologia, Universidade Federal Fluminense, 113 pp.

ARAÚJO EFS, SILVA CG, REIS AT, PEROVANO R, GORINI C, VENDEVILLE BC \& ALBUQUERQUE NC. 2009. Movimentos de massa multiescala na Bacia da Foz do Amazonas - Margem Equatorial Brasileira. Revista Brasileira de Geofísica, 27(3): 485-508.

AZEVEDO RP. 1991. Interpretation of a deep seismic reflection profile in the Pará-Maranhão Basin. In: Congresso Internacional da Sociedade Brasileira de Geofísica, 2., Salvador-BA, Anais, 661-666.

BRANDÃO JASL \& FEIJÓ FJ. 1994. Bacia da Foz do Amazonas. Boletim de Geociências da Petrobras, 8: 9-99.

BRUCE CH. 1973. Pressure shale and related sediment deformation mechanism for development of regional contemporaneous faults. AAPG Bulletin, 57: 878-886.

BRUNO GLG. 1987. Argilocinese no Cone do Amazonas, Bacia da Foz do Amazonas. Departamento de Geologia da Universidade Federal de Ouro Preto - UFOP. Dissertação de Mestrado. Ouro Preto - MG. 103 pp.

BUTLER R \& MCCAFFREY B. 2008. Depositional control on structural evolution in gravitationally-failing submarine slope systems. In: TURNER J \& BUTLER R. Conference on Gravitational Collapse at Continental Margins: Products and Processes. 28-29 October 2008, London. The Geological Society at Burlington House, London, Abstract book, p. 16.

CALDEIRA JL, COUTINHO LFC \& MORAES MFB. 1991. Aspectos estruturais e sismoestratigráficos da seção Neo-Cretácea e Terciária da Bacia de Barreirinhas - Águas profundas. In: SBGf Congresso Internacional da Sociedade Brasileira de Geofísica, 2., Salvador. Anais, 667-672.

COBBOLD PR \& SZATMARI P. 1991. Radial gravitational gliding on passive margins. Tectonophysics, 188: 249-289.

COBBOLD PR, ROSSELO EA \& VENDEVILLE BC. 1989. Some experiments on interacting sedimentation and deformation above salt horizons. Bull. Soc. Géol. France, 8(3): 453-460.
COBBOLD PR, SZATMARI P, DEMERCIAN S, COELHO D \& ROSSELLO EA. 1995. Seismic and experimental evidence of thin-skinned extension in the deep-water province of the Cabo Frio region, Rio de Janeiro, Brazil. In: JACKSON MPA, ROBERTS DG \& SNELSON S (Eds.). Salt tectonics: a global perspective. AAPG Memoir, 65: 323-332.

COBBOLD PR, MOURGES R \& BOYD K. 2004. Mechanism of thinskinned detachment in the Amazon Fan: assessing the importance of fluid overpressure and hydrocarbon generation. Marine and Petroleum Geology, 21: 1013-1025.

COHEN HA \& MCCLAY K. 1996. Sedimentation and shale tectonics of the northwestern Niger Delta front. Marine and Petroleum Geology, 13: 313-328.

DA SILVA RJP. 2008. Colapso gravitacional e estruturação da seção marinha da Bacia da Foz do Amazonas no contexto de múltiplos níveis de destacamento. Dissertação de Mestrado. Departamento de Geologia Universidade Federal Fluminense. Niterói - RJ. 101 pp.

DAHLEN FA, SUPPE J \& DAVIS D. 1984. Mechanics of fold-and-thrust belts and accretionary wedges: cohesive Coulomb theory. Journal of Geophysical Research, 89: 10,087-10,101.

DUVAL B, CRAMEZ C \& JACKSON MPA. 1992. Raft tectonics in the Kwanza Basin, Angola. Marine and Petroleum Geology, 9: 389-404.

FIGUEIREDO JJP, ZALÁN PV \& SOARES EF. 2007. Bacia da Foz do Amazonas. In: MILANI ED, RANGEL HD, BUENO GV, STICA JM, WINTER WR, CAIXETA JM \& PESSOA NETO OC (Eds.). Cartas estratigráficas. Boletim de Geociências da Petrobras, 15(2): 299-309.

FIGUEIREDO J, HOORN P, VAN DER VEN P \& SOARES EF. 2009. Late Miocene onset of the Amazon River and the Amazon Deep-sea Fan: evidence from the Foz do Amazonas Basin. Geology, 37(7): 619-622.

FLOOD RD \& PIPER DJW. 1997. Amazon Fan sedimentation: the relationship to Equatorial climate change, continental denudation, and sealevel fluctuations. In: FLOOD RD, PIPER DJW, KLAUS A \& PETERSON LC (Eds.). Proceedings of the Ocean Drilling Program, Scientific Results, 155: 653-675.

FRANKE MR. 1975. Pressões de formação anormalmente altas. Boletim Técnico da Petrobras, 18(2): 52-66.

GE H, JACKSON MPA \& VENDEVILLE BC. 1997. Kinematics and dynamics of salt tectonics driven by progradation. AAPG Bulletin, 81: 398423.

GREGORY-WODZICKI KM. 2000. Uplift history of the Central and Northern Andes: a review. GSA Bull., 112: 1091-1105.

GUIMARÃES PTM, MACHADO ER \& SILVA SRP. 1989. Interpretação sismo-estratigráfica em águas profundas na Bacia do Pará-Maranhão. In: Sintex, Seminário de Interpretação Exploratória, 1, Petrobras - Departamento de Exploração, Rio de Janeiro, Anais, 171-183.

HOOPER RJ, FITZSOMMONS RJ, GRANT N \& VENDEVILLE BC. 2002. The role of deformation in controlling depositional patterns in the 
south-central Niger Delta, West Africa. Journal of Structural Geology, 24: 847-859.

HUDEC MR \& JACKSON MPA. 2007. Terra infirma: Understanding salt tectonics. Earth-Science Reviews, 82(1-2): 1-28.

JACKSON MPA \& CRAMEZ C. 1989. Seismic recognition of salt welds in salt tectonics regimes, SEPM Gulf Coast Section Tenth Annual Research Conference Program and Abstracts, Houston, Texas, p. 66-71.

JACKSON MPA, VENDEVILLE BC \& SCHULTZ-ELA DD. 1994. Structural dynamics of salt systems. Annual Review of Earth and Planetary Sciences, 22: 93-117.

JACKSON MPA, ROBERTS DG \& SNELSON S. 1995. Salt tectonics: a global perspective. AAPG Memoir, 65: 454 pp.

JENYON MK. 1986. Salt tectonics. Elsevier, London, 191 pp.

KOYI HA \& VENDEVILLE BC. 2003. The effect of décollement dip on geometry and kinematics of model accretionary wedges. Journal of Structural Geology, 25: 1445-1450.

KRÉZSEK C, ADAM J \& GRUJIC D. 2007. Mechanics of fault and expulsion rollover systems developed on passive margins detached on salt: Insights from analogue modelling and optical strain monitoring. Geological Society of London, Special Publications, 292: 103-121.

LECOMTE E \& VENDEVILLE BC. 2008. Analogue modelling and numerical simulations of gravitational spreading along passive margin under fluid overpressure. International Geological Modelling Conference. Florence, Italy. Abstract. CD-ROM.

LOPEZ M. 2001. Architecture and depositional pattern of the Quaternary deep-sea fan of the Amazon. Marine and Petroleum Geology, 18: 479486.

MASLIN M \& MIKKELSEN N. 1997. Amazon fan mass-transport deposits and underlying interglacial deposits: age estimates and fan dynamics. In: FLOOD RD, PIPER DJW, KLAUS A \& PETERSON LC (Eds.). Proceedings of the Ocean Drilling Program, Scientific Results, Amazon Fan. Ocean Drilling Program, College Station, TX, 155: 353-365.

MASLIN M, VILELA C, MIKKELSEN N \& GRO0TES P. 2005. Causes of catastrophic sediment failures of the Amazon Fan. Quaternary Science Reviews, 24: 2180-2193.

MATOS RMD. 1999. From oblique rifting to a transform margin: the opening of the Equatorial Atlantic. In: SBGf, International Congress of the Brazilian Geophysical Society, 6, Rio de Janeiro, 1, CD-ROM.

MATOS RMD. 2000. Tectonic evolution of the Equatorial South Atlantic. In: MOHRIAK W \& TALWANI M (Eds.). Atlantic Rifts and Continental Margins. American Geophysical Union, Geophysical Monograph Series, 115: 331-354.

McCLAY KR. 1990. Extensional fault systems in sedimentary basins: a review of analogue model studies. Marine and Petroleum Geology, 7: 206-233.
MITCHUM RM, VAIL PR \& SANGREE JB. 1977a. Seismic stratigraphy and global changes of sea level, part 6: Seismic stratigraphy interpretation procedures. In: PAYTON CE (Ed.). Seismic Stratigraphy: Application to Hydrocarbon Exploration. AAPG Memoir, 26: 117-133.

MITCHUM RM, VAIL PR \& SANGREE JB. 1977b. Seismic stratigraphy and global changes of sea level, part 7: Seismic stratigraphic interpretation procedures. In: PAYTON CE (Ed.). Seismic Stratigraphy: Application to Hydrocarbon Exploration. AAPG Memoir, 26: 135-143.

MOHRIAK WU, MACEDO JM, CASTELLANI RT, RANGEL HD, BARROS AZN, LATGÉ MAL, RICCI JA, MIZUSAKI AMP, SZATMARI P, DEMERCIAN LS, RIZZO JG \& AIRES JR. 1995. Salt Tectonics and Structural Styles in the Deep-water Province of the Cabo Frio Region, Rio de Janeiro, Brazil. In: JACKSON MPA, ROBERTS DG \& SNELSON S (Eds.). Salt tectonics: a global perspective. AAPG Memoir, 65: 273-304.

MORLEY CK \& GUERIN G. 1996. Comparison of gravity-driven deformation styles and behavior associated with mobile shales and salt. Tectonics, 15: 1154-1170.

MOURGUES R \& COBBOLD PR. 2003. Some tectonic consequences of fluid overpressures and seepage forces as demonstrated by sandbox modelling. Tectonophysics, 376: 75-97.

MOURGUES R \& COBBOLD PR. 2006a. Sandbox experiments on gravitational spreading and gliding in the presence of fluid overpressures. Journal of Structural Geology, 28: 887-906.

MOURGUES R \& COBBOLD PR. 2006b. Thrust wedges and fluid overpressures: Sandbox models involving pore fluids. J. Geophys. Res., 111, B05404, doi: 10.1029/2004JB003441.

OLIVEIRA V. 2005. A tectônica Gravitacional no Cone do Amazonas: Compartimentação Estrutural e Mecanismos Controladores. Departamento de Geologia da Universidade Federal Fluminense - UFF. Dissertação de Mestrado. Niterói - RJ. 83 pp.

REIS AT, GORINI C \& MAUFFRET A. 2005. Implications of Salt-sediment Interactions for the Architecture of the Gulf of Lions deep-water sedimentary systems - Western Mediterranean Sea, Gulf of Lions Special Issue, Marine and Petroleum Geology, 22(6-7): 713-746.

REIS AT, SILVA CG, VENDEVILLE BC, PEROVANO R, FERREIRA E, GORINI C, ALBUQUERQUE N, PEDERNEIRAS R, ALBUQUERQUE V \& MATTIODA J. 2008. Gravity-driven processes at the offshore Amazon Mouth Basin - Brazilian Equatorial Atlantic margin. Gravitational Collapse at Continental Margins: Products and Processes. The Geological Society of London. p. 15.

REIS AT, PEROVANO RJ, SILVA CG, VENDEVILLE BC, ARAÚJO EFS \& GORINI C. no prelo. Two-scale gravitational collapse in the Amazon Deep-sea Fan: a coupled system of gravity tectonics and mass wasting processes. Journal of the Geological Society of London, $12 \mathrm{pp}$. 
RENSBERGEN PV, HILLIS RR, MALTMAN AJ \& MORLEY CK. 2003. Subsurface sediment mobilization: introduction. Geological Society of London, Special Publications, 216: 1-8.

RIMINGTON N, CRAMP A \& MORTON A. 2000. Amazon Fan sands: implications for provenance. Marine and Petroleum Geology, 17: 267-284.

ROWAN MG, JACKSON MPA \& TRUDGILL BD. 1999. Salt-related fault families and fault welds in the Northern Gulf of Mexico. AAPG Bulletin, 83(9): 1454-1484.

ROWAN MG, TRUDGILL BD \& FIDUK JC. 2000. Deep-water, saltcored foldbelts: Lessons from the Mississippi Fan and Perdido foldbelts, Northern Gulf of Mexico. In: MOHRIAK W \& TALWANI M (Eds.). Atlantic rifts and continental margins. American Geophysical Union, Geophysical Monograph Series, 115: 173-191.

ROWAN MG, PEEL FJ \& VENDEVILLE BC. 2004. Gravity driven fold belts on passive margins. In: MCCLAY KR (Ed.). Thrust tectonics and hydrocarbon systems. AAPG Memoir, 82: 157-182.

SCHULTZ-ELA DD. 2001. Excursus on gravity gliding and gravity spreading. Journal of Structural Geology, 23: 725-731.

SILVA SRP \& RODARTE JBM. 1989. Bacias da Foz do Amazonas e Pará (águas profundas): uma análise sismoestratigráfica, tectonosedimentar e térmica. In: Anais do I Congresso da Sociedade Brasileira de Geofísica, Rio de Janeiro, Resumos, 2: 843-852.

SILVA SRP, MACIEL RR \& SEVERINO MCG. 1999. Cenozoic Tectonics of Amazon Mouth Basin. Geo-Marine Letters, 18: 256-262.

SILVA CG, FERREIRA E, REIS AT, PEROVANO R, GORINI C, VENDEVILLE BC \& ALBUQUERQUE N. 2009. Megaslides in the Foz do Amazonas Basin-Brazilian equatorial margin. In: MOSHER DC, SHIPP C, MOSCARDELLI L, CHAYTOR J, BAXTER C, LEE H \& URGELES R (Eds.). Submarine Mass Movements and Their Consequences, Series Advances in Natural and Technological Research. 1 ed. Amsterdam: Springer, 28, 567-577.

SMITH WHF \& SANDWELL DT. 1997. Global sea floor topography from satellite altimetry and ship depth soundings. Science, 277: 1956-1962.

SULTAN N, VOISSET M, MARSSET B, MARSSET T, CAUQUIL E \& COLLIAT J-L. 2007. Potential role of compressional structures in generating submarine slope failures in the Niger Delta. Marine Geology, 237: 169-190.

VENDEVILLE BC. 1991. Thin-skinned compressional structures above frictional-plastic and viscous décollement layers. Geological Society of America, Abstract with Programs, 23(5): A423.
VENDEVILLE BC. 2005a. Similarities and differences between salt and shale tectonics. European Geosciences Union. Geophysical Research Abstracts, 7: 03575.

VENDEVILLE BC. 2005b. Salt tectonics driven by sediment progradation: Part I - Mechanics and kinematics: AAPG Bulletin, 89: 1071-1079.

VENDEVILLE BC \& COBBOLD PR. 1987. Glissements gravitaires synsédimentaires et failles normales listriques: modèles expérimentaux. Comptes Rendus de l'Académie des Sciences de Paris. p. 1313-1319.

VENDEVILLE B \& COBBOLD PR. 1988. How normal faulting and sedimentation interact to produce listric fault profiles and stratigraphic wedges. Journal of Structural Geology, 10(7): 649-659.

VENDEVILLE BC \& JACKSON MPA. 1992a. The rise of diapirs during thin-skinned extension. Marine and Petroleum Geology, 9(4): 331-353.

VENDEVILLE BC \& JACKSON MPA. 1992b. The fall of diapirs during thin-skinned extension. Marine and Petroleum Geology, 9(4): 354-371.

VENDEVILLE BC \& GAULLIER V. 2003. Role of pore-fluid pressure and slope angle in triggering submarine mass movements: Natural examples and pilot experimental models. In: LOCAT J \& MIENERT J (Eds.). Submarine mass movements and their consequences. First International Symposium: Netherlands, Kluwer Academic Publishers, p. 137-144.

WORRALL DM \& SNELSON S. 1989. Evolution of the northern Gulf of Mexico, with emphasis on Cenozoic growth faulting and the role of salt. In: BALLY AW \& PALMER AR (Eds.). The Geology of North America: an overview. Geological Society of America, The Geology of North America, A: $97-138$.

WU S \& BALLY AW. 2000. Slope tectonics - comparisons and contrasts of structural styles of salt and shale tectonics of the northern Gulf of Mexico with shale tectonics of offshore Nigeria in Gulf of Guinea. In: MOHRIAK W \& TALWANI M (Eds.). Atlantic Rifts and Continental Margins. American Geophysical Union, Geophysical Monograph Series, 115: 151-172.

ZALÁN PV. 1999. Seismic expression and internal order of gravitational fold-and-thrust belts in Brazilian deep waters. In: VI International Congress of the Brazilian Geophysical Society, Rio de Janeiro, Expanded Abstracts. CD-ROM.

ZALÁN PV. 2005. End members of gravitational fold and thrust belts (GFTBS) in the deep waters of Brazil, 2005. In: SHAW JH, CONNORS C \& SUPPE J (Eds.). Seismic Interpretation of Contractional Fault-Related Folds. An American Association of Petroleum Geologists Seismic Atlas, 53: 147-153. 


\section{NOTAS SOBRE OS AUTORES}

Rodrigo Perovano é graduado em Oceanografia pela Universidade do Estado do Rio de Janeiro - UERJ (2006) e mestre em Geologia e Geofísica Marinha pelo LAGEMAR/UFF (2008). Atualmente cursa doutorado no LAGEMAR - UFF e na Université de Lille 1 (França), na temática de tectônica gravitacional induzida por níveis superpressurizados na Bacia da Foz do Amazonas, Margem Equatorial Brasileira. Suas áreas de interesse são tectônica gravitacional e relação tectônica-sedimentação em sistemas sedimentares de águas profundas.

Antonio Tadeu dos Reis é bacharel em Geologia pela Universidade Federal do Rio de Janeiro - UFRJ (1985), mestre em Geofísica pelo Observatório Nacional - CNPa (1994) e doutor em Análise de Bacias pela Université Pierre et Marie Curie - Paris VI, França (2001). Atualmente é professor adjunto da Faculdade de Oceanografia - UERJ. Suas áreas de interesse são processos gravitacionais (tectônica e transporte de massa), análise de bacias, e ciclicidade e arquitetura sedimentar de sistemas deposicionais marinhos.

Cleverson Guizan Silva é bacharel em Geologia pela Universidade Federal do Rio de Janeiro - UFRJ (1982), mestre em Geologia pela Universidade Federal do Rio de Janeiro (1987) e doutor em Geologia pela Universidade Duke-EUA (1991). Atualmente é professor associado da Universidade Federal Fluminense - UFF. Seus temas de interesse inserem-se em geologia e geofísica marinha, como sistemas deposicionais marinhos e costeiros, tectônica de argilas, hidratos de gás e instabilidades do talude, diagnóstico e monitoramento ambiental em áreas marinhas e costeiras.

Bruno C. Vendeville possui doutorado pela Universidade de Rennes, França (1987). A partir do pós-doutorado em 1988 e 1989 no Centro de Tectonofísica, Universidade A\&M do Texas, trabalhou no escritório de Geologia Econômica na Universidade do Texas em Austin por 15 anos. Desde 2004 é professor na Universidade de Ciências e Tecnologia de Lille, norte da França. Suas áreas de interesse incluem tectônica de sal e argilas bem como modelos tectônicos experimentais e processos gravitacionais em diversas escalas.

Christian Gorini possui doutorado em Geologia Estrutural pela Université Paul Sabatier, Toulouse III, França (1994). Atualmente é professor do Departamento de Tectônica e Modelização de Bacias Sedimentares - UMR 7072, Université Pierre et Marie Curie, Paris VI, França. Suas áreas de interesse são análise de bacias, tectônica gravitacional e processos sedimentares marinhos.

Valterlene de Oliveira é bacharel em Geologia pela Universidade Federal da Bahia - UFBA (2002) e mestre em Geologia e Geofísica Marinha pelo LAGEMAR Universidade Federal Fluminense (2005). Atualmente trabalha na Petróleo Brasileiro S.A. - PETROBRAS como geóloga na Bacia do Recôncavo. Suas áreas de interesse são interpretação sísmica, sismo-estratigrafia, petrofísica e modelização estrutural.

Érika Ferreira da Silva Araújo é graduada em Oceanografia pela Universidade do Estado do Rio de Janeiro - UERJ (2006) e mestre em Geologia e Geofísica Marinha pelo LAGEMAR/UFF (2008). Atualmente cursa doutorado no LAGEMAR - UFF e na Université de Lille 1 (França) na temática de instabilidade gravitacional (deslizamentos de massa) no Leque Submarino do Amazonas, Margem Equatorial Brasileira. Suas áreas de interesse são processos gravitacionais em margens passivas e arquitetura sedimentar de sistemas turbidíticos. 